\title{
Cold-Atmospheric Plasma Induces Tumor Cell Death in Preclinical In Vivo and In Vitro Models of Human Cholangiocarcinoma
}

\author{
Javier Vaquero ${ }^{1,2,3,4, *(0)}$, Florian Judée ${ }^{2}$, Marie Vallette ${ }^{1}$, Henri Decauchy ${ }^{2}$, Ander Arbelaiz ${ }^{1}$, \\ Lynda Aoudjehane 1,5, Olivier Scatton 1,5,6, Ester Gonzalez-Sanchez 1,3,4, Fatiha Merabtene 1, \\ Jérémy Augustin ${ }^{1}\left(\mathbb{D}\right.$, Chantal Housset ${ }^{1,5,7}$, Thierry Dufour ${ }^{2, *,+}$ and Laura Fouassier ${ }^{1, *,+}+(\mathbb{D})$ \\ 1 Institut National de la Santé et de la Recherche Médicale (Inserm), Centre de Recherche Saint-Antoine, \\ CRSA, Sorbonne Université, 75012 Paris, France; marie-v@neuf.fr (M.V.); aarbelaizcossio@gmail.com (A.A.); \\ lynda.aoudjehane@gmail.com (L.A.); olivier.scatton@gmail.com (O.S.); \\ m.gonzalezsanchez@idibell.cat (E.G.-S.); fatiha.merabtene@inserm.fr (F.M.); jrm.augustin@gmail.com (J.A.); \\ chantal.housset@inserm.fr (C.H.) \\ 2 LPP (Laboratoire de Physique des Plasmas, UMR 7648), Sorbonne Université, Centre National de la \\ Recherche Scientifique (CNRS), Ecole Polytechnique, 75005 Paris, France; florian.judee@uca.fr (F.J.); \\ henri.decauchy@sorbonne-universite.fr (H.D.) \\ 3 TGF- $\beta$ and Cancer Group, Oncobell Program, Bellvitge Biomedical Research Institute (IDIBELL), \\ 08908 Barcelona, Spain \\ 4 Oncology Program, CIBEREHD, National Biomedical Research Institute on Liver and Gastrointestinal \\ Diseases, Instituto de Salud Carlos III, 28029 Madrid, Spain \\ 5 Inserm, Institute of Cardiometabolism and Nutrition (ICAN), Sorbonne Université, 75013 Paris, France \\ 6 Department of Hepatobiliary Surgery and Liver Transplantation, Pitié-Salpêtrière Hospital, \\ Assistance Publique-Hôpitaux de Paris (AP-HP), 75013 Paris, France \\ 7 Department of Hepatology, Reference Center for Inflammatory Biliary Diseases and Autoimmune \\ Hepatitis (Centre de Référence Maladies Rares (CRMR), Maladies Inflammatoires des Voies Biliaires et \\ Hépatites Auto-Immunes (MIVB-H), AP-HP, 75012 Paris, France \\ * Correspondence: jvaquero@idibell.cat (J.V.); thierry.dufour@sorbonne-universite.fr (T.D.); \\ laura.fouassier@inserm.fr (L.F.); Tel.: +34-626569867 (J.V.); +33-144279236 (T.D.); +33-698774001 (L.F.) \\ + Co-senior authors.
}

Received: 23 April 2020; Accepted: 15 May 2020; Published: 19 May 2020

\begin{abstract}
Through the last decade, cold atmospheric plasma (CAP) has emerged as an innovative therapeutic option for cancer treatment. Recently, we have set up a potentially safe atmospheric pressure plasma jet device that displays antitumoral properties in a preclinical model of cholangiocarcinoma (CCA), a rare and very aggressive cancer emerging from the biliary tree with few efficient treatments. In the present study, we aimed at deciphering the molecular mechanisms underlying the antitumor effects of CAP towards CCA in both an in vivo and in vitro context. In vivo, using subcutaneous xenografts into immunocompromised mice, CAP treatment of CCA induced DNA lesions and tumor cell apoptosis, as evaluated by 8-oxoguanine and cleaved caspase-3 immunohistochemistry, respectively. The analysis of the tumor microenvironment showed changes in markers related to macrophage polarization. In vitro, the incubation of CCA cells with CAP-treated culture media (i.e., plasma-activated media, PAM) led to a dose response decrease in cell survival. At molecular level, CAP treatment induced double-strand DNA breaks, followed by an increased phosphorylation and activation of the cell cycle master regulators $\mathrm{CHK} 1$ and p53, leading to cell cycle arrest and cell death by apoptosis. In conclusion, CAP is a novel therapeutic option to consider for CCA in the future.
\end{abstract}

Keywords: cholangiocarcinoma; cold plasma; innovative therapy; tumor cells; macrophages; plasma selectivity; plasma jet 


\section{Introduction}

Cholangiocarcinoma (CCA) is a tumor of the biliary tree with poor prognosis that is characterized by a dense desmoplastic stroma [1]. CCA is a rare tumor. Currently, CCA accounts for $3 \%$ of all gastrointestinal cancers, but overall its incidence tends to increase worldwide. So far, surgical resection of the tumor is the only curative and effective therapeutic option. However, this cancer is usually diagnosed at advanced stage, so that this treatment is feasible in a small proportion of patients and recurrence is high. When tumor resection is not possible or when recurrence occurs, the therapeutic alternatives consist in palliative treatments based on chemotherapy regimens with poor results [2]. Hence, there is a need for new therapeutic approaches.

Cold atmospheric plasma (CAP) (named also non-thermal plasma or low temperature plasma) is a weakly ionized gas that is created by electrical discharges, composed of transient, energetic, and chemical active species (electrons, ions, metastables, radicals) that displays radiation, gas dynamics and electric field properties. Today, CAP interaction with biological systems (cells, tissues, tumors) is studied to address medical issues, such as blood clotting, wound healing, dentistry, repair surgery, cosmetics, infectious and inflammatory diseases, and oncology [3]. CAP science and technology appear as a new research avenue to provide breakthrough solutions where conventional therapies in cancer appear limited [3]. Indeed, plasmas can reduce the cell proliferation or tumor volume in preclinical mice models, in several types of cancers, including skin, pancreatic, bladder, and colon $[4,5]$. Therefore, plasmas have major potential in driving antitumor effects, notably in resistant tumors, such as CCA. The primary action of CAP is to generate long-lived molecules, such as reactive oxygen and nitrogen species (RONS), mainly from nitrogen and oxygen in atmospheric air or solution. This action can be either beneficial or deleterious on living tissues, depending on their concentrations. RONS are primarily responsible for the anti-tumor activity of CAP. They drive cell cycle arrest and cell death by damaging DNA and regulating cancer-relevant molecules, such as the tumor suppressor p53 [6,7].

To date, only two studies addressed the potential of CAP to treat liver tumors $[5,8]$. In these studies, CAP was tested on hepatocellular carcinoma cell lines and induced cell death. We previously engineered a new cold plasma jet device that showed significant antitumor effects in a mouse CCA model, without inducing toxic effects on heathy tissue, in order to investigate CAP as a potential new therapeutic option [9]. Here, we aim to gain insight into the molecular mechanisms by which CAP halts CCA development and progression in vivo and in vitro. In addition, we investigated whether CAP has an effect on non-tumoral cells notably hepatocytes, the parenchymal liver cells. Evidence was previously provided to indicate that CAP induced cell death selectively in tumor cells and not in non-malignant cells [3]. The tumor itself is a complex tissue structure, including cells of the tumor microenvironment, such as cancer-associated fibroblasts (CAF), endothelial cells (EC), and tumor-associated macrophages (TAM). Therefore, we also evaluated in vivo the impact of CAP on these cell populations.

\section{Results}

\subsection{Cold Atmospheric Plasma Treatment Reduces Cholangiocarcinoma Progression in a Murine Xenograft Model}

We previously compared two CAP generating devices, i.e., Plasma Gun (PG) and Plasma Tesla Jet (PTJ), showing that both devices were safe, but differed with respect to anticancer properties [9]. Only PTJ (Figure 1a) displayed a significant therapeutic efficacy in a subcutaneous xenograft model of CCA [9]. In the present study, we used the same model to further analyze the molecular mechanisms accounting for PTJ effects in the same preclinical model. In order to better assess the effect of CAP on CCA growth, we compared its effect with that of gemcitabine, one of the chemotherapeutic drugs currently used in CCA patient treatment. 
(a)

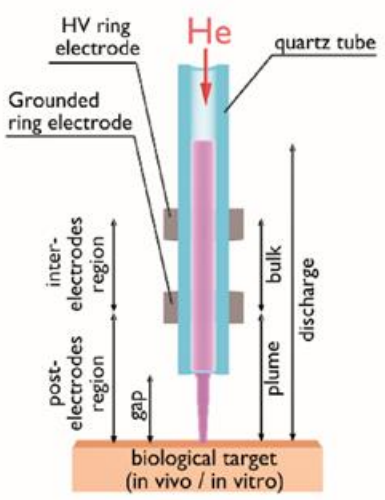

(c)

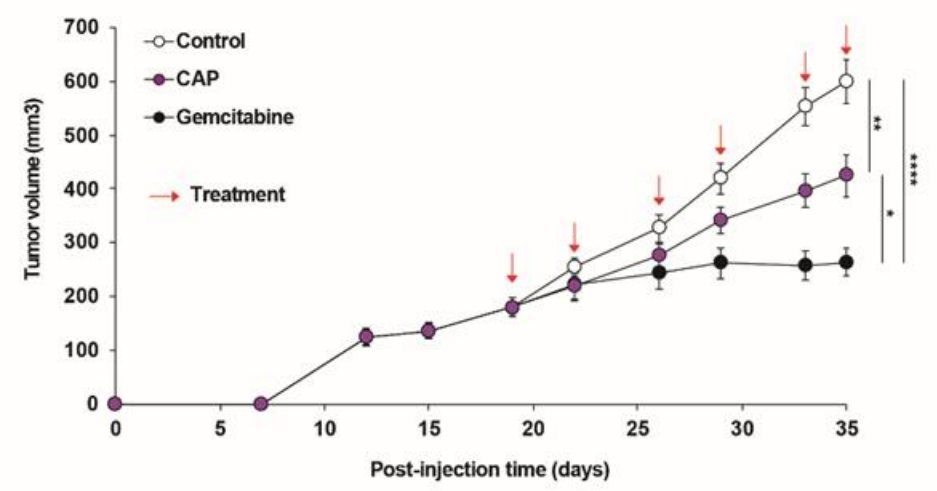

(b)
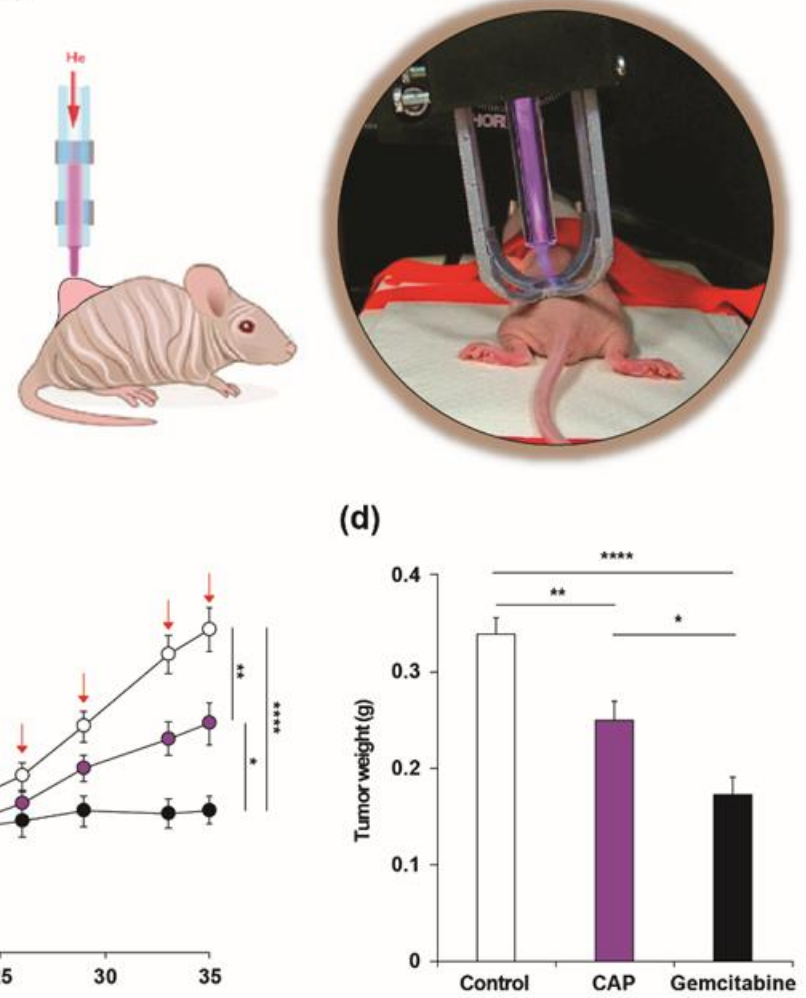

(d)

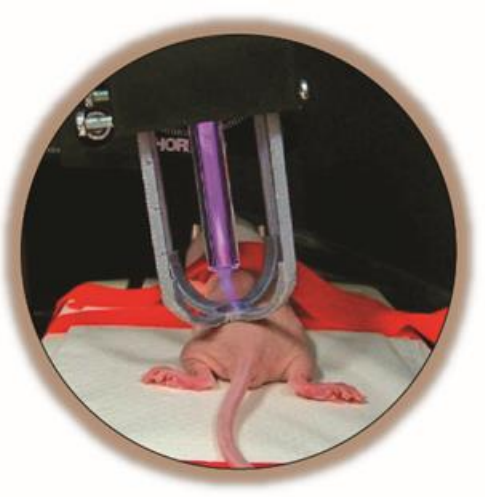

(e)

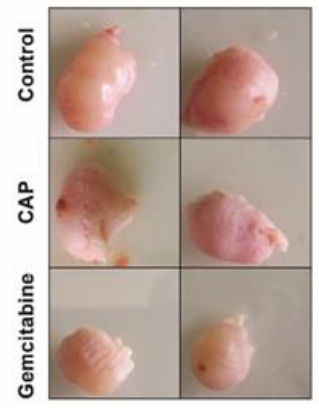

(f)

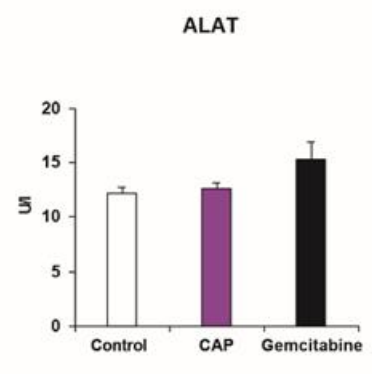

Figure 1. (a) Experimental setup of the Plasma Tesla Jet device (PTJ). (b) Schematic representation and representative image of the cold atmospheric plasma (CAP) application to subcutaneous xenograft cholangiocarcinoma (CCA) tumors. (c) Tumor volume of mice bearing CCA developed from EGI-1 cells treated with gemcitabine $(120 \mathrm{mg} / \mathrm{kg}$, black circles), CAP (1 min. at $9 \mathrm{kV}$ of amplitude, frequency $=30 \mathrm{kHz}$, duty cycle $=14 \%$, gap $=10 \mathrm{~mm}$, purple circles) or untreated (control, white circles). Arrows indicate treatments points with CAP and gemcitabine. (d) Tumor weight at sacrifice (day 35). (e) Representative images of tumors from each group at sacrifice. (f) Plasmatic concentrations of alanine aminotransferase (ALAT), aspartate aminotransferase (ASAT) and lactate dehydrogenase (LDH). Values are expressed as means \pm SEM. ${ }^{*}, p<0.05 ; * *, p<0.01 ; * * *, p<0.001 ; * * *, p<0.0001$.

EGI-1 CCA cells were injected to induce tumors in the flank of immunodeficient mice and, once the tumors reached an arbitrary volume of $200 \mathrm{~mm}^{3}$, we applied CAP directly on the tumors (Figure 1b) or we administrated gemcitabine by intraperitoneal injection twice a week for three weeks (see red arrows in Figure 1c). Animals were sacrificed $2 \mathrm{~h}$ after the last treatment. Tumor size and growth rate were significantly reduced after the application of CAP (Figure 1c-e) consistently with our previous results [9]. The well-established antitumoral effect of gemcitabine was evident and it exceeded that of CAP [10]. We measured the plasma concentrations of alanine aminotransferase (ALAT) and 
aspartate aminotransferase (ASAT) as well as lactate dehydrogenase (LDH) in treated mice to verify that local CAP treatment did not induce side effects in the whole organism. No significant difference of concentration was observed between CAP treated animals and controls (Figure 1f). By contrast, ASAT and LDH were significantly increased in the animals that received gemcitabine, indicating liver damage (Figure 1f). These results show the advantage of direct CAP treatment, which remains local over the systemic effects of gemcitabine, but also less toxic. If, at first sight, CAP might appear less efficient than gemcitabine, one has to underline that CAP exposure times were as low as $1 \mathrm{~min}$., while the lifetime of gemcitabine injected in the organism is several hours.

\subsection{Cold Atmospheric Plasma Induces Apoptosis in Cholangiocarcinoma Cells In Vivo}

We performed a histological analysis of the tumors to further evaluate the effect of CAP on CCA xenografts. A deep analysis revealed the presence of purple round structures that represent calcifications (Figure 2a,b). These calcifications are often associated with apoptotic bodies and they may represent a late state of condensed apoptotic structures. The quantification showed an increased number of calcifications in tumors treated with CAP or gemcitabine when compared to the controls (Figure 2c).

(a)

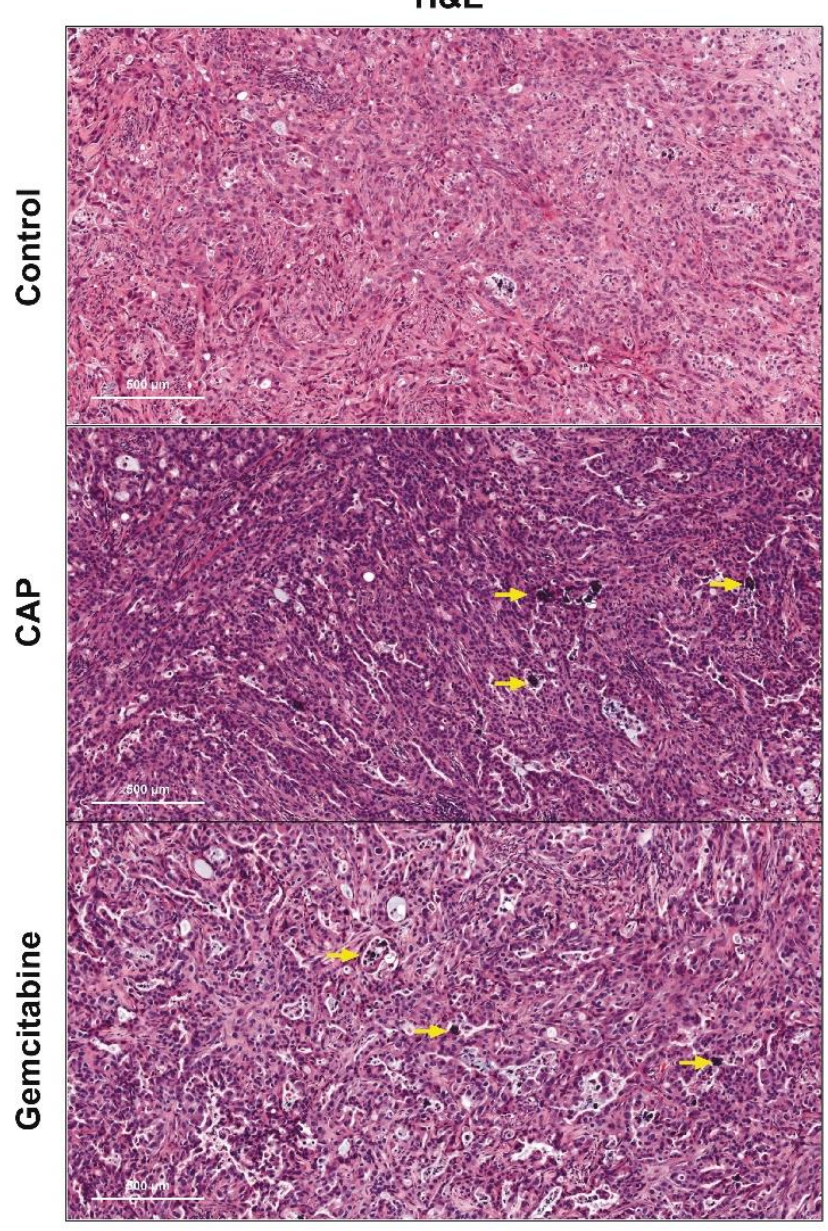

(b)

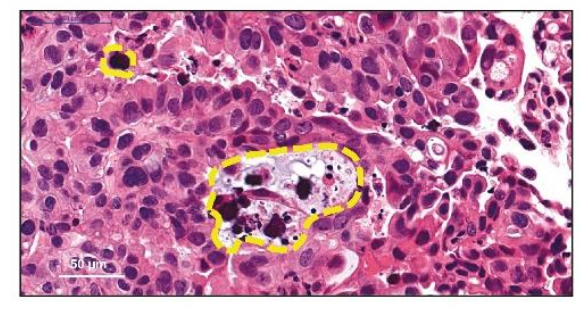

(c)

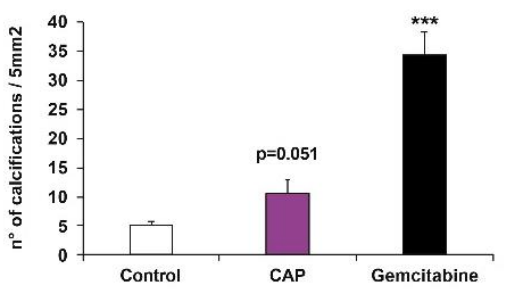

Figure 2. (a) Representative HE staining of control (upper panel), CAP (middle panel) and gemcitabine (bottom panel) treated xenograft tumors. Magnification $\times 125$. Scale: $500 \mu \mathrm{m}$. (b) Magnification $(\times 1000)$ of calcifications corresponding to apoptotic bodies (outlined in yellow). Scale: $50 \mu \mathrm{m}$. (c) Quantification of apoptotic structures. ${ }^{* * *}, p<0.001$; compared with control tumors. 
The presence of these calcifications prompted us to study apoptosis, the main type of cell death related to CAP, by performing immunostaining against cleaved caspase-3 (cCaspase-3), a critical executioner of apoptosis that is responsible for the cleavage of many key proteins. Animals treated with CAP showed an intense staining of cCaspase-3 in some areas of the tumors when compared to the controls, as shown in Figure 3 (left panels). This staining was also present, but weaker in animals that received gemcitabine. These differences that can be explained by the time at which the animals were sacrificed, i.e., approximately $2 \mathrm{~h}$ after CAP or gemcitabine treatments. Since CAP is applied locally, its effects operate faster than drugs that are delivered intraperitoneally, such as gemcitabine. Indeed, this drug must be first absorbed and then transported to the tumors. In that latter case, the therapeutic effects of gemcitabine may be observed later than $2 \mathrm{~h}$.

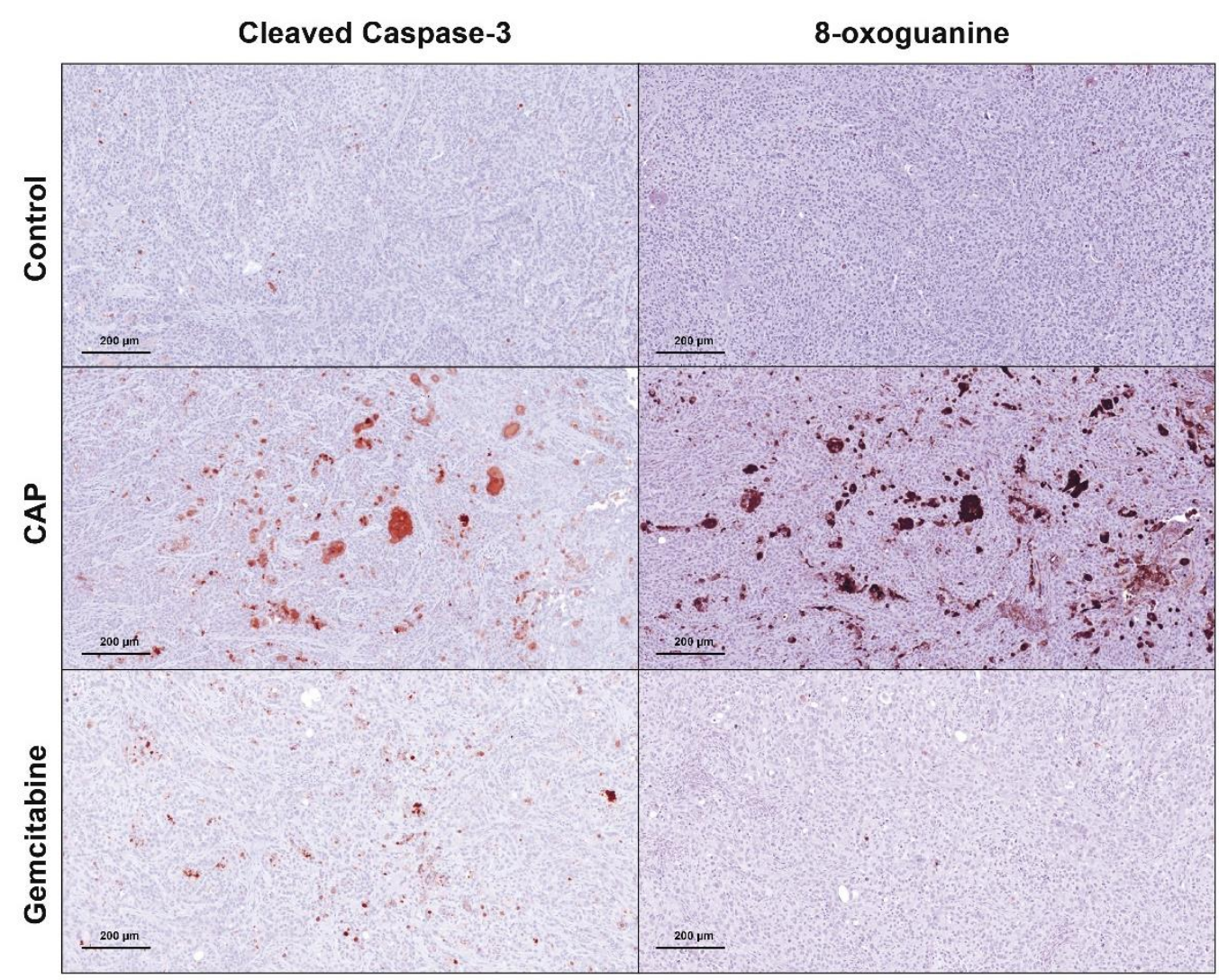

Figure 3. Representative IHC staining of cleaved caspase-3 and 8-oxoguanine in control (upper panel), CAP (middle panel) and gemcitabine (bottom panel) treated xenograft tumors. Magnification, $\times 250$. Scale: $200 \mu \mathrm{m}$.

We evaluated the presence of cellular components altered as a result of reactive species overload, more specifically 8-oxoguanine, one of the major products of DNA oxidation, as an event that could unchain the signaling pathways leading to cell death by apoptosis, since one of the main effects of CAP is the production of RONS. CAP treatment was able to strongly induce DNA alterations, as shown in Figure 3 (right panels). In addition, it is worth noting that these alterations were colocalized with the areas positive for cleaved caspase-3 (left panels). This perfect overlapping enables us to bridge DNA damage with cell apoptosis. Interestingly, there was no staining of 8-oxoguanine in tumors from the group that received gemcitabine, showing that the main effects of this drug are not mediated by reactive species related molecular mechanisms. 


\subsection{Cold Atmospheric Plasma Reduces Viability of Cholangiocarcinoma Cells but Not of Normal Hepatocytes In Vitro}

Next, we performed in vitro studies on CCA cell lines to further dissect the effects that are induced by CAP on tumor cells. First, we evaluated the effects of CAP treatment on the viability of two human CCA cell lines, EGI-1, the same cell line used for the induction of subcutaneous xenografts, and HuCCT1. Besides, to verify whether CAP treatment is biologically selective, non-malignant primary human hepatocytes, the main cell type in the liver, where isolated from patients. They were also exposed to the same CAP treatment to verify whether CAP might drive to side effects. We first treated by plasma a standard volume of fresh culture media $(3 \mathrm{~mL})$ in a standardized plastic support (6-well plates) for $3 \mathrm{~min}$ in order to standardize the application of CAP across the different in vitro experiments. Second, we incubated the resulting plasma-activated culture media (commonly called PAM) with either CCA cell lines or human hepatocytes in culture (Figure S1). Such indirect CAP treatment induced a decrease in the viability of CCA cells and this effect became stronger for CAP exposure times increasing from 1 to $10 \mathrm{~min}$. (Figure 4a). In contrast, no effect was observed on the viability of human hepatocytes isolated from 3 different patients (Figure 4a), hence demonstrating a selective effect of CAP on tumor cells over non-malignant liver cells. Of note, similar experiments performed after exposure to gemcitabine showed a dose-dependent decrease in cell viability that was more pronounced in CCA cells, but reached an approximately $30 \%$ reduction in hepatocytes (Figure 4b), demonstrating a better selectivity of CAP over gemcitabine. We evaluated the production of RONS in media since CCA cell lines and primary hepatocytes need different culture media due to specific requirements of each cell type. More specifically, we determined the concentration of $\mathrm{NO}_{2}$ and $\mathrm{H}_{2} \mathrm{O}_{2}$ in CAP-exposed culture media at different time points, the same used in cell viability studies. While the production of $\mathrm{NO}_{2}$ remains overall the same over treatment time in both types of media (Figure 4c), production of $\mathrm{H}_{2} \mathrm{O}_{2}$, was approximately six times higher in hepatocyte media than in CCA media (Figure 4d). To get more insight on this issue we determined the generation of ROS in cell lysates from CCA cells and hepatocytes exposed to PAM. Interestingly, production of $\mathrm{H}_{2} \mathrm{O}_{2}$ was only increased in CCA cells exposed to PAM, while it remained unchanged in hepatocytes (Figure 4e). This observation led us to think about potential defense mechanisms protecting hepatocytes from ROS production, more specifically, ROS-scavenging enzymes. Indeed, further analysis revealed that the mRNA expression of several enzymes was strongly increased in hepatocytes when compared to both CCA cell lines (Figure 4f). Altogether, these results validate the selective effect of CAP-activated medium in CCA cells over hepatocytes.

\subsection{Cold Atmospheric Plasma Induces Cell Cycle Arrest and Apoptosis in Cholangiocarcinoma Cells}

CAP-derived RONS drive cell cycle arrest and cell death by damaging DNA, as previously underlined [6,7]. For the following experiments we used the IC50 from the viability assays (Figure 4a), corresponding to 3-min. treatment with CAP. Therefore, we evaluated the possibility of cell cycle arrest in our experimental conditions. Indeed, flow cytometry analysis of cell cycle distribution showed changes in the different phases (Figure 5). EGI-1 and HuCCT1 cells both experienced a decrease in the percentage of cells in G0/G1 phases and S, and an increase of the percentage of cells in G2/M phases.

The accumulation of cells in G2/M indicate that cells arrested the cell cycle at the G2/M DNA damage checkpoint, which serves to prevent cells with genomic DNA damage from entering the $\mathrm{M}$ phase. Therefore, our next step was to determine whether, as observed in vivo, CAP treatment could drive DNA damage in CCA cells in vitro. One of the most important proteins required for checkpoint-mediated cell cycle arrest and DNA repair following double-stranded DNA breaks is the histone H2AX. DNA damage that is caused by oxidative stress results in a rapid phosphorylation of $\mathrm{H} 2 \mathrm{AX}$ (named $\gamma \mathrm{H} 2 \mathrm{AX}$ ), which leads to the recruitment of several proteins in response to DNA damage. Immunofluorescence analysis showed a strong staining of phospho-histone $\mathrm{H} 2 \mathrm{AX}$ in both EGI-1 and HuCCT1 cells at different times (i.e., $24 \mathrm{~h}, 48 \mathrm{~h}$ and $72 \mathrm{~h}$ ) after exposure to CAP-activated culture medium compared to untreated cells (Figure 6a,d), being $72 \mathrm{~h}$ in EGI-1 and $48 \mathrm{~h}$ in HuCCT1 
cells, the highest signal, as ascertained by western blot (Figure 6b,c,e,f and Figures S3-S10). Western blot analyses showed a clear correlation between the increase of histone H2AX phosphorylation and PARP cleavage (Figure 6b-e and Figures S3-S10), a marker of cell apoptosis.

(a)

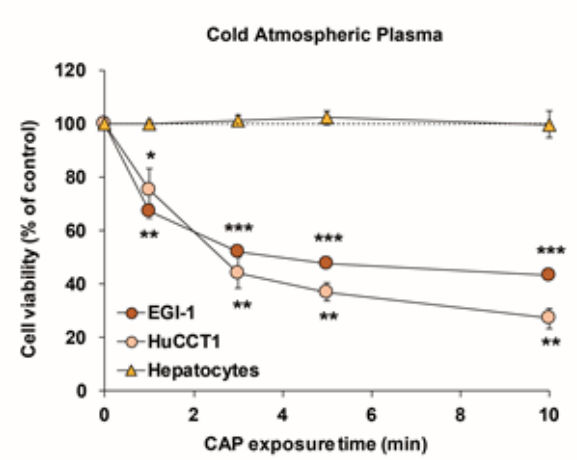

(c)

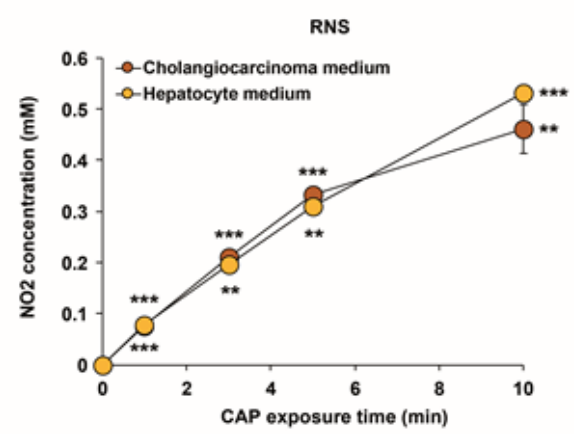

(e)

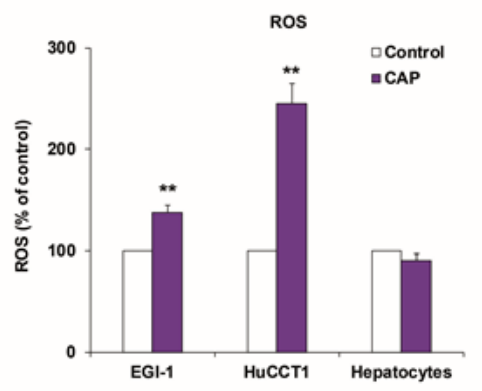

(b)

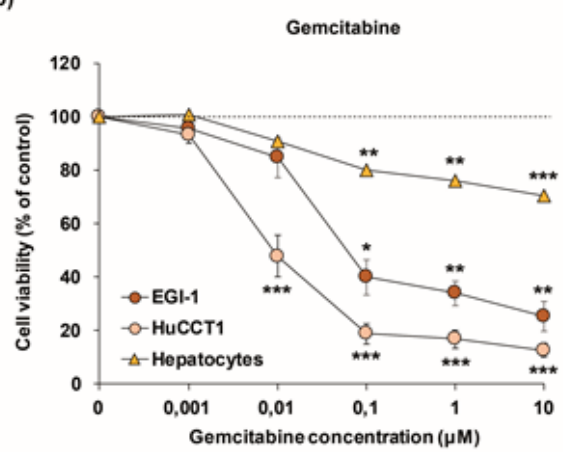

(d)
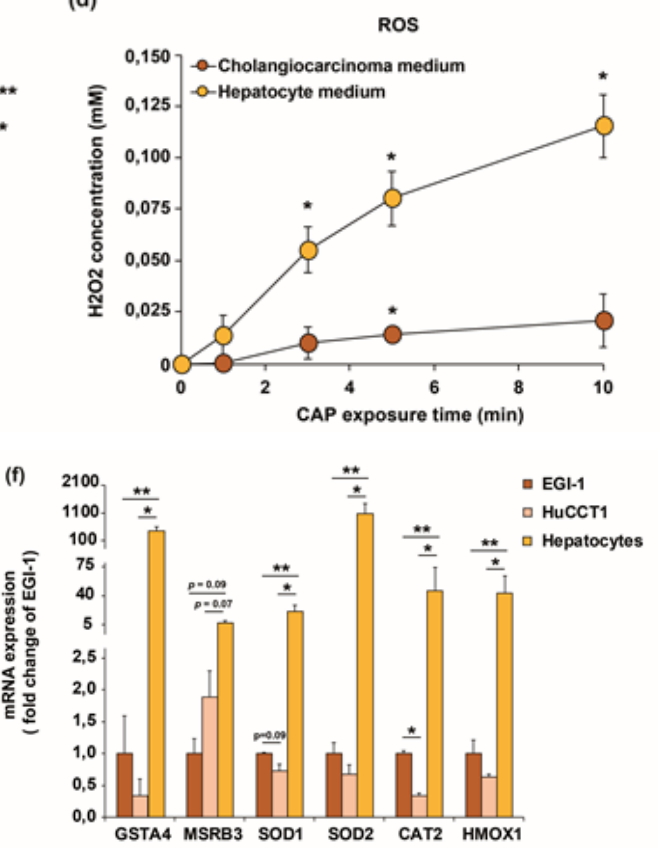

Figure 4. $(\mathbf{a}, \mathbf{b})$ Effect of CAP (a) and gemcitabine (b) on the viability of EGI-1 and HuCCT1 CCA cells and human primary hepatocytes. Cell viability was measured after incubation for $72 \mathrm{~h}$ with culture medium previously treated for 1,3, 5, and $10 \mathrm{~min}$. with CAP $(9 \mathrm{kV}, 30 \mathrm{kHz}, 14 \%$, gap of $7 \mathrm{~mm})$. (c,d) $\mathrm{NO}_{2}$ (c) and $\mathrm{H}_{2} \mathrm{O}_{2}$ (d) determination in culture media from CCA cells and primary hepatocytes. (e) $\mathrm{H}_{2} \mathrm{O}_{2}$ determination in cell lysates from CCA cells and primary hepatocytes exposed to PAM for 3 min. (f) Expression of GSTA4, MSRB3, SOD1, SOD2, CAT2, and HMOX1 at mRNA level in CCA cell and hepatocytes. Values are expressed as means \pm SEM from at least three independent cultures. ${ }^{*}, p<0.05 ;{ }^{* *}, p<0.01 ;{ }^{* * *}, p<0.001$; compared with untreated cells $(0 \mathrm{~min}$.).

We evaluated the activation of the two parallel signaling pathways that ultimately break the cell cycle once the DNA damage is sensed to better decipher the mechanism of cell cycle arrest in CCA cells treated with CAP. These signaling cascades that block the progression to mitosis are led by CHK kinases and p53, respectively. Western blot analysis from Figure $7 \mathrm{~b}, \mathrm{c}, \mathrm{e}, \mathrm{f}$ showed a strong phosphorylation of both $\mathrm{CHK} 1$ and p53 from $24 \mathrm{~h}$ to $72 \mathrm{~h}$ in both cell lines. These results suggest that the cell cycle is arrested soon after CAP-activated culture medium exposure, when DNA damage is first detected, but apoptosis is not induced until the accumulation of DNA damage is strong enough, which is $72 \mathrm{~h}$ after exposure to CAP in EGI-1 and $48 \mathrm{~h}$ in HuCCT1 cells. Interestingly, CAP exposure of hepatocytes 
showed a reduced expression of CHK1 and p53 when compared to CCA cells (Figures S2a and S11), probably due to the low proliferative capacity of these cells in primary culture. Additionally, no changes in H2AX phosphorylation or PARP cleavage were observed, indicating the absence of DNA damage and corroborating the selective capacity of CAP in hepatocytes (Figures S2a and S11).

(a)

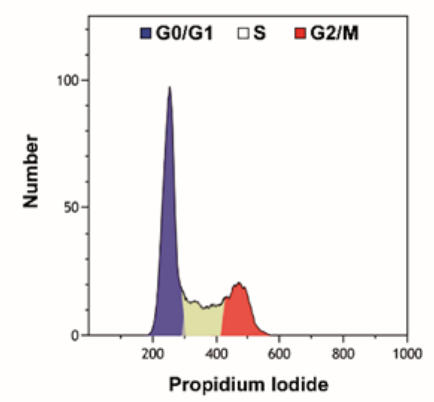

(c)

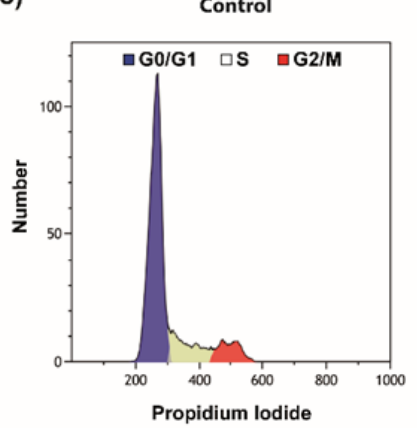

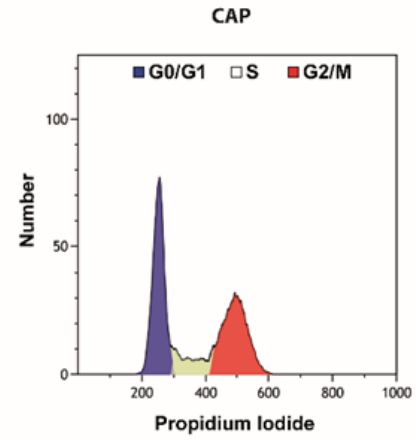

CAP

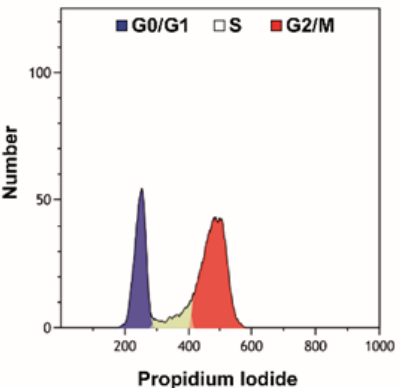

(b)

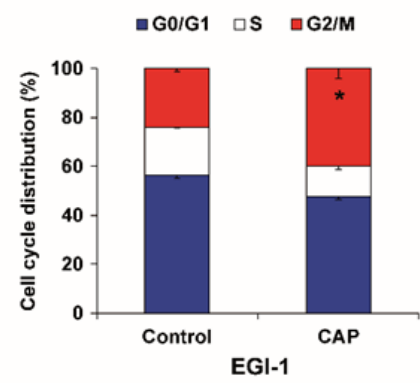

(d)

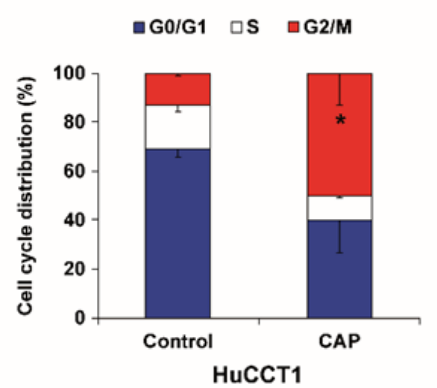

Figure 5. (a-d) Representative flow cytometry cell cycle measurement $(\mathbf{a}, \mathbf{c})$ and graphical representation of the cell cycle distribution (b,d) of EGI- $1(\mathbf{a}, \mathbf{b})$ and HuCCT1 $(\mathbf{c}, \mathbf{d})$ CCA cells after $24 \mathrm{~h}$ of exposure to culture medium pretreated with CAP for $3 \mathrm{~min}$. ( $9 \mathrm{kV}, 30 \mathrm{kHz}, 14 \%$, gap of $7 \mathrm{~mm}$ ). Cell populations in G0/G1, S, and G2/M phases are given as percentage of total cells. Values are expressed as means \pm SEM from at least three independent cultures. ${ }^{*}, p<0.05$; as compared with control cells.

(a)

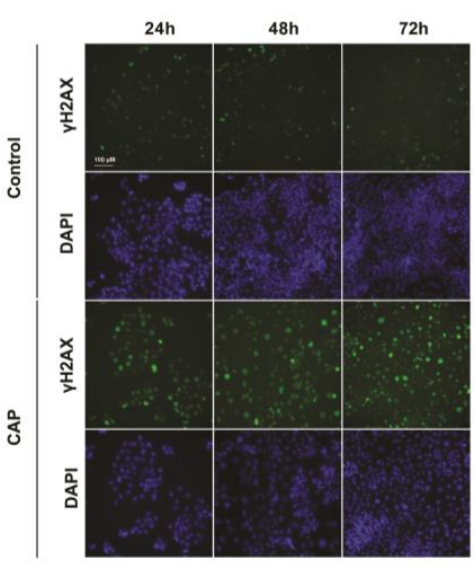

(b)

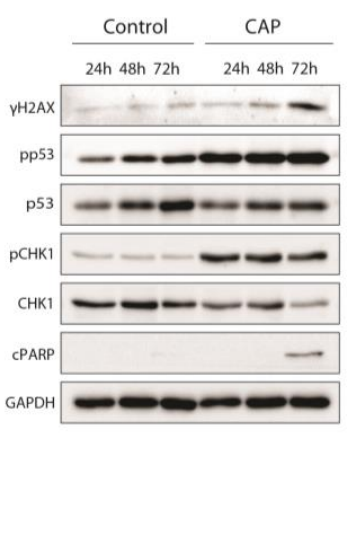

(c)
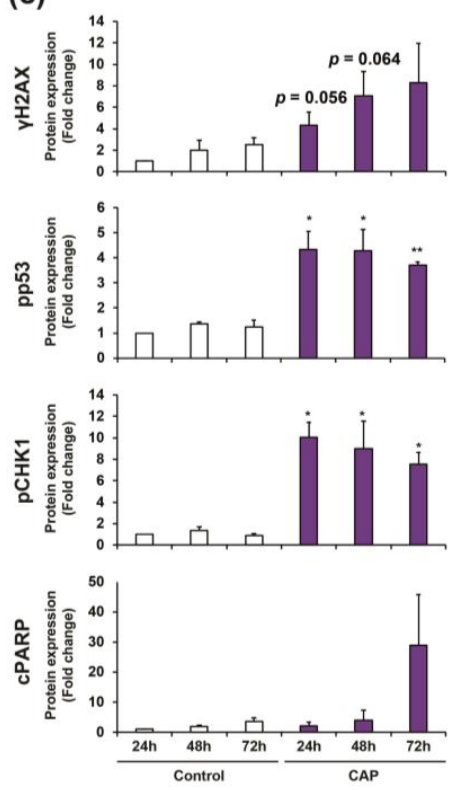

Figure 6. Cont. 
(d)

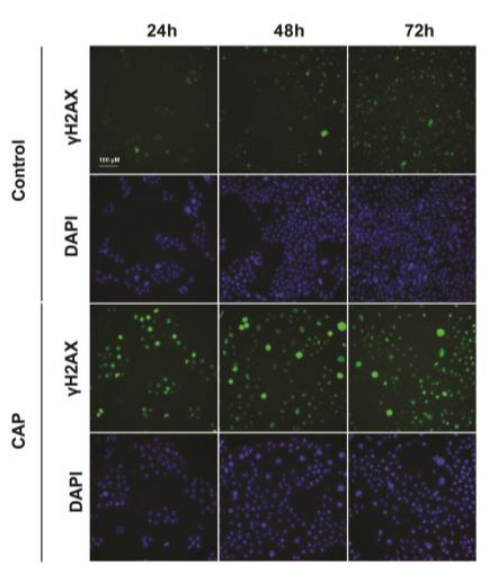

(e)

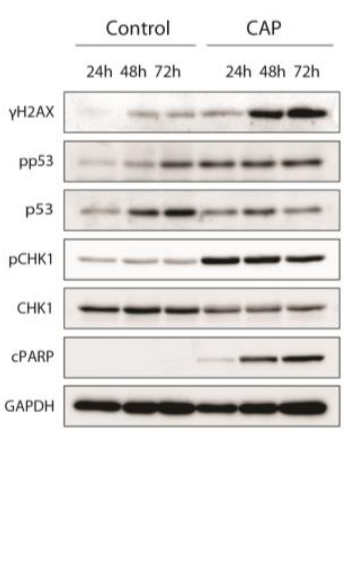

(f)
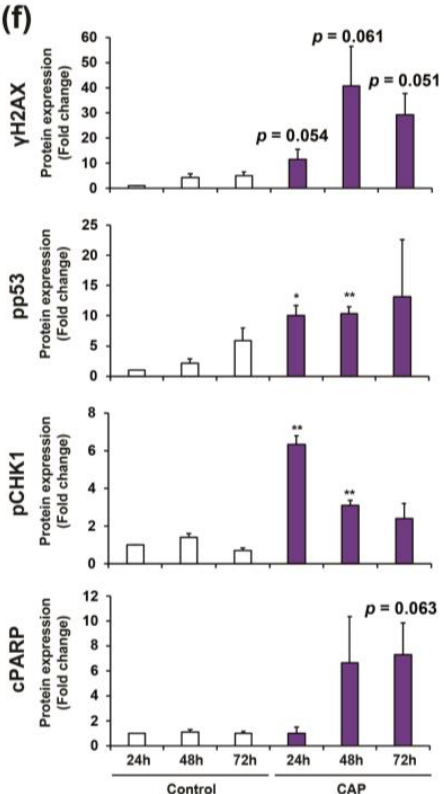

Figure 6. (a,d) Representative images of phosphorylated $\mathrm{H} 2 \mathrm{AX}(\gamma \mathrm{H} 2 \mathrm{AX})$ analyzed by immunofluorescence in EGI-1 (a) and HuCCT1 (d) CCA cells after $24 \mathrm{~h}, 48 \mathrm{~h}$ and $72 \mathrm{~h}$ of exposure to culture medium pretreated with CAP for $3 \mathrm{~min}$. ( $9 \mathrm{kV}, 30 \mathrm{kHz}, 14 \%$, gap of $7 \mathrm{~mm})$. Magnification, $\times 10$. (b,e) Representative images of western blot analysis of cleaved PARP, phosphorylated and total p53, phosphorylated and total CHK1 and phosphorylated H2AX in EGI-1 (b) and HuCCT1 (e) cells treated in the same conditions. (c,f) Densitometry analysis of western blot from cleaved PARP, phosphorylated p53, phosphorylated $\mathrm{CHK} 1$, and phosphorylated H2AX. Values are expressed as means \pm SEM from three independent cultures. ${ }^{*}, p<0.05 ;{ }^{* *}, p<0.01$; compared with control cells.

(a)

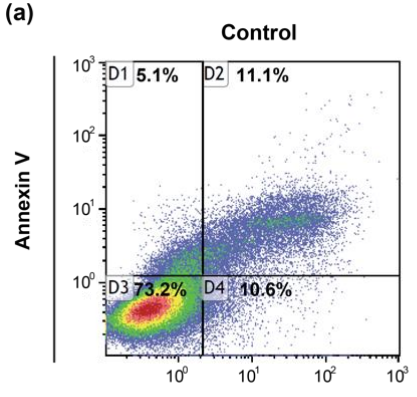

(b)
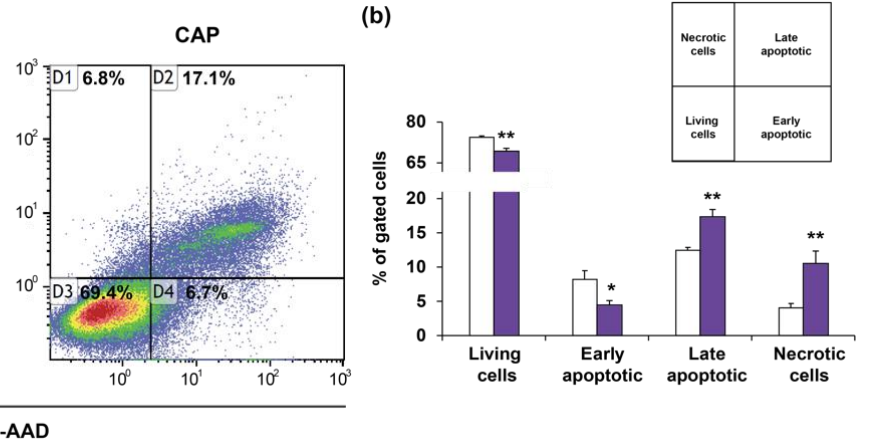

(c)

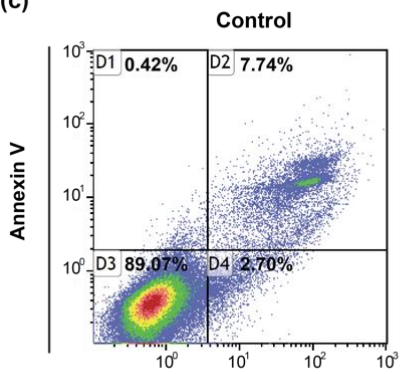

(d)

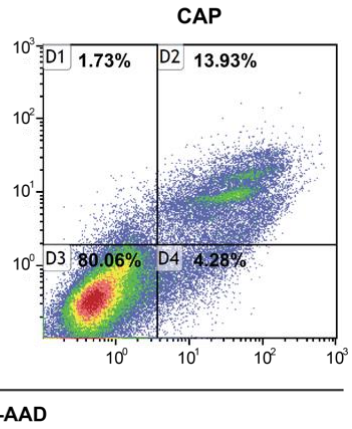

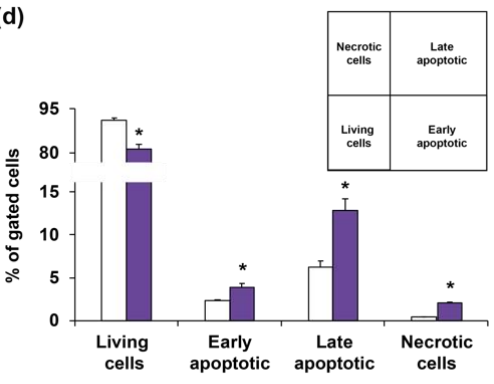

Figure 7. (a-d) Representative images $(\mathbf{a}, \mathbf{c})$ and quantification $(\mathbf{b}, \mathbf{d})$ of apoptosis by flow cytometry analysis of Annexin V/7AAD in EGI-1 $(\mathbf{a}, \mathbf{b})$ and HuCCT1 $(\mathbf{c}, \mathbf{d})$ CCA cells after $48 \mathrm{~h}$ of exposure to PAM for $3 \mathrm{~min}$. ( $9 \mathrm{kV}, 30 \mathrm{kHz}, 14 \%$, gap of $7 \mathrm{~mm}$ ). Values are expressed as means $\pm \mathrm{SEM}$ from at least three independent cultures. ${ }^{*}, p<0.05 ;{ }^{* *}, p<0.01$; compared with control condition. 
When these experiments were reproduced after exposure to gemcitabine, we observed similar results in terms of increase of $\mathrm{H} 2 \mathrm{AX}, \mathrm{CHK} 1$, and p53 phosphorylation, accompanied by PARP cleavage in both CCA cell lines (Figures S2b, S12 and S13). Interestingly, gemcitabine induces DNA damage in hepatocytes in a dose dependent manner (Figures S2c and S14), concordant with the decrease in viability that is observed in Figure $4 \mathrm{~b}$, and this DNA damage started as early as $24 \mathrm{~h}$ after exposure and was maintained until $72 \mathrm{~h}$, as ascertained by H2AX phosphorylation (Figures S2d and S15). However, no change was observed in the phosphorylation of CHK1 and p53 or PARP cleavage, indicating that the reduction in hepatocyte viability induced by gemcitabine might not be related to cell cycle arrest and apoptosis, but other types of dead, such as necrosis or senescence.

Finally, we verified that the decrease in cell viability of EGI-1 and HuCCT1 after CAP treatment was due to apoptosis. Indeed, the exposure of cells to PAM reduces the number of viable cells and increases the populations in the quadrants corresponding to late-apoptotic and necrotic cells in both cell types (Figure 7a-d), as ascertained by Annexin V-7AAD quantification by flow cytometry. Of note, this increase in apoptotic cells was observed in HuCCT1 at $48 \mathrm{~h}$, but it was not in EGI-1 at this time, only becoming evident at $72 \mathrm{~h}$ in the later. These results may corroborate that apoptosis is not induced until the accumulation of DNA damage is strong enough, that is $72 \mathrm{~h}$ after exposure to PAM in EGI-1 and $48 \mathrm{~h}$ in $\mathrm{HuCCT} 1$ cells.

\subsection{Cold Atmospheric Plasma Affects the Phenotype of Tumor-Associated Macrophage}

Besides the effects of CAP on tumor cells, we sought to determine whether CAP exposure might have any effect on the stroma of the EGI-1 subcutaneous xenograft model. This model has the advantage of providing the opportunity of evaluating the expression of human genes, corresponding to the injected tumor CCA cells, and murine genes, corresponding to the cells forming the stroma that are recruited by cancer cells during tumor formation. Therefore, we examined the mRNA expression of different specific markers corresponding to cancer-associated fibroblasts (CAF) (Acta2, coding alpha-SMA), endothelial cells (EC) (Pecam1, coding for CD31), and tumor-associated macrophages (TAM) (Adgre1, coding for F4/80). There were no significant changes in the mRNA of Acta 2 or Pecam 1 among the different groups (Figure 8a). However, the expression of Adgre1 increased in the tumors from the animals that received CAP or gemcitabine treatment when compared to the controls, suggesting a potential enhanced recruitment and/or proliferation of TAM in the treated tumors (Figure 8a). The presence of TAM in tumor from the different groups was evidenced by immunohistochemical analyses of $\mathrm{F} 4 / 80$, as shown in representative images from each group (Figure $8 \mathrm{~b}$ ), although it was impossible to properly determine the differences in macrophage infiltration by F4/80 IHC quantification. However, we decided to perform a preliminary analysis to elucidate this point based on previous publications indicating a phenotypic change of macrophages in absence of changes in the total number of these cells after exposure to experimental therapies [11]. Analysis of Ccl2 (coding for Monocyte chemotactic protein-1, MCP-1) and Ccr2, a chemokine and its receptor, respectively, which are major regulators of monocyte chemotaxis and macrophage trafficking, showed an increased expression in groups that were treated with CAP and gemcitabine when compared to the controls (Figure 8c), which might suggest changes in chemotactic response of resident TAM. In addition, CAP was able to increase the expression of several cytokines that are associated with the antitumor phenotype of macrophages and that are involved in the induction of apoptosis, i.e., Tnfa (coding for Tnf $\alpha$ ), Tnfsf1 (coding for TNF-related apoptosis-inducing ligand (Trail)) and Il1b (coding for Il1 $\beta$ ) (Figure $8 \mathrm{~d}$ ). These results are in accordance with previous publications that link CAP treatment with the modulation of immune cells and together with the increasing interest of immunotherapies as cancer treatment validate the need for further investigation on this topic in CCA. 
(a)

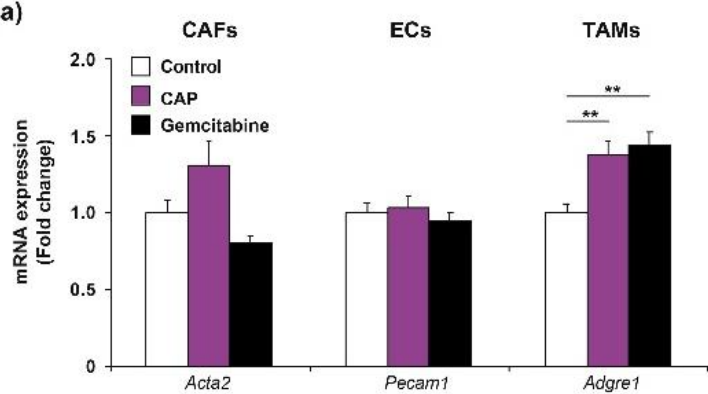

(c)

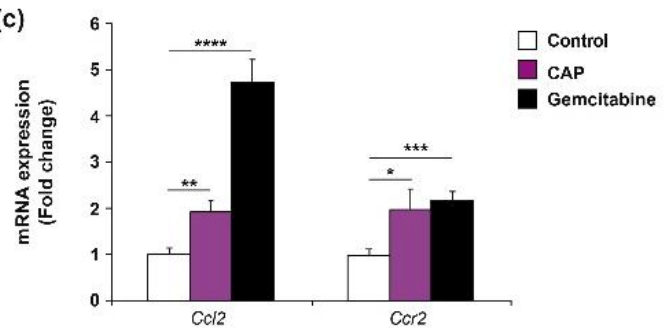

(d)

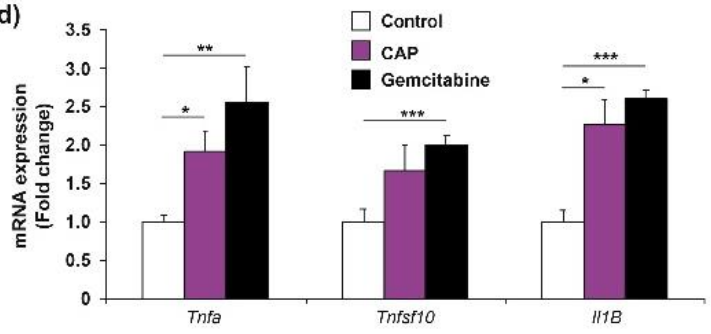

(b)

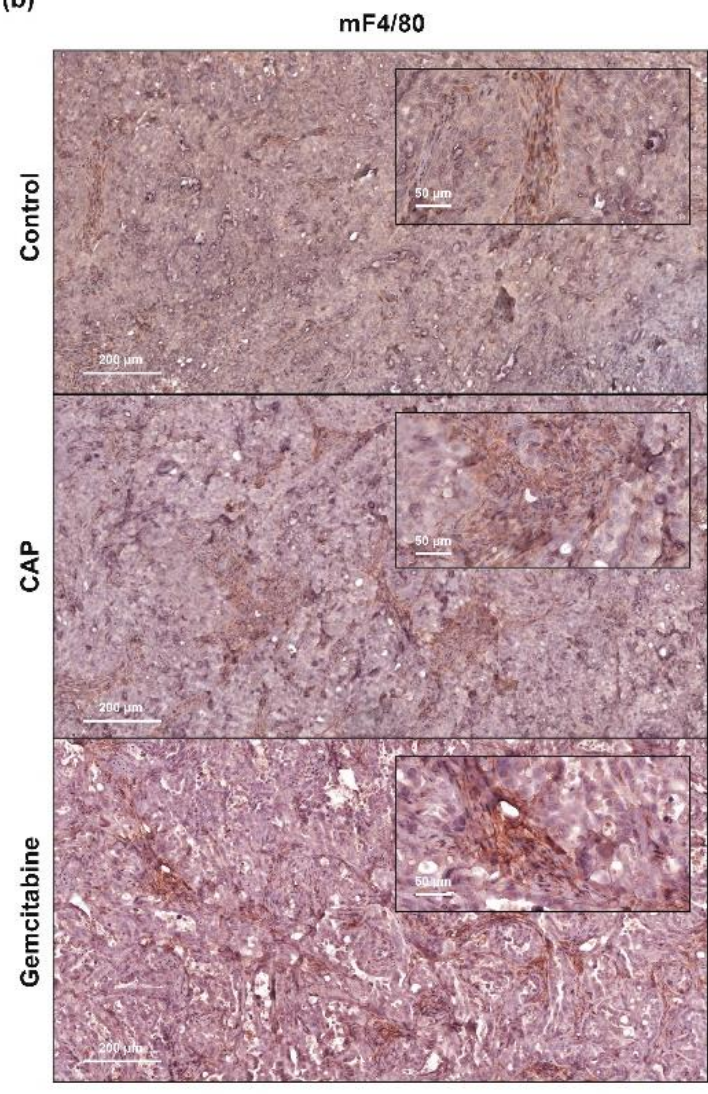

Figure 8. (a) Changes in mRNA expression of cell type markers (Acta2/ $\alpha$-SMA, a marker of cancer-associated fibroblasts CAFs, Pecam1/CD31, a marker of endothelial cells (EC) and Adgre1/F4/80, a marker of tumor-associated macrophages (TAM) in control (white bars), CAP (purple bars) and gemcitabine (black bars) treated xenograft tumors. (c) Representative IHC staining of F4/80 in the same tumors. Magnification $\times 250$ (inserts $\times 1000$ ). Scale: $200 \mu \mathrm{m}$. (b) Changes in mRNA expression of Ccl2/Mcp1 and Ccr2 (c) in control (white bars), CAP (purple bars) and gemcitabine (black bars) treated xenograft tumors. (d) Changes in mRNA expression of pro-apoptotic cytokines (Tnfa/Tnf $\alpha$, Tnfsf1/Trail and $I l 1 b / \mathrm{Il} 1 \beta$ ) in control (white bars), CAP (purple bars), and gemcitabine (black bars) treated xenograft tumors. Values are expressed as means \pm SEM. ${ }^{*}, p<0.05 ;{ }^{* *}, p<0.01 ;{ }^{* * *}, p<0.001{ }^{* * * *}, p<0.0001$; compared with control tumors.

\section{Discussion}

In the present work, we analyzed the effects of CAP in vivo in a mouse xenograft model of CCA and in vitro on human CCA cell lines, as well as on non-malignant human hepatocytes. We found that local application of CAP on the tumor halts its growth without inducing systemic side effects. The analysis of tumors showed areas of calcification suggesting cell dead, which was confirmed by immunostaining of cleaved-caspase-3, a protein of the apoptotic pathway, along with DNA lesions due to plasma-originated reactive species. In vitro, CAP-activated medium contains reactive species (e.g., nitrites) that induced oxidative stress and reduced cell survival by arresting the cell cycle and inducing apoptosis in CCA cells but not in hepatocytes. Finally, preliminary analysis suggested changes in the surrounding stroma of CCA tumors after exposure to CAP.

Since the early 2000s, CAP have generated a lot of interest in cancer medicine as a promising treatment for cancer without inducing systemic toxic side effect. The anti-tumor properties of CAP are now well established and tumor volume reductions have been demonstrated in murine tumor models of several cancer types, including pancreatic [12,13], ovary [14], breast [15] and colon [16], melanoma [17], and glioblastoma [6,18]. We investigated if CAP might drive to anti-cancer effects 
in vivo since CCA is a very aggressive tumor with a limited therapeutic arsenal. We conducted further studies to decipher in a deeper way the cellular mechanisms behind CAP effect based on our previous work that aimed to set up a safe device with anti-tumor properties in CCA [9]. Up to date, the only two studies dealing with the effects of CAP on liver cancer were performed in hepatocellular carcinoma cell lines [5,8]. Thus, this study is the first conducted on CCA while using in vivo and in vitro preclinical models.

Only $5 \%$ of the studies published so far include in vivo experiments, owing to the emerging and highly multidisciplinary aspects of "cold plasma oncology" [19]. Most CAP studies in cancer have been achieved while using tumor cell lines originating from either solid or blood tumors and rarely on mouse tumor models. We conducted in vivo studies to analyze the effects of CAP on death and oxidative stress, and we compared this treatment to conventional treatment with gemcitabine. In our study, CAP demonstrated anti-tumor properties although a traditional chemotherapeutic agent such as gemcitabine showed higher efficiency. Interestingly, CAP was locally applied on a very small tumor surface for a very short period of time $(1 \mathrm{~min})$ demonstrating no side effects, while gemcitabine, which was applied intraperitoneally, was accompanied by an increased plasmatic concentration of markers indicating liver damage. Even if few studies have been performed in vivo, some of them confirmed that CAP has no systemic effects. Liedtle et al. have addressed this point through a complete study showing that CAP by using plasma-activated medium does not affect blood parameters, leucocyte distribution, or cytokine signature [20]. However, classical blood parameters to evaluate liver and cell toxicity, such as transaminases and LDH, were not measured, in contrast to our study. Studies using orthotopic CCA model are required to evaluate the direct effect of CAP on liver parenchyma in spite of our in vitro observation on primary hepatocytes and the absence of liver damage in vivo. Nevertheless, further investigation to improve the surface exposure and the time of treatment with CAP is crucial in order to obtain the maximum benefit from this new therapeutic tool.

At the cellular level, histology examination of the tumor showed signs of calcification, a reaction occurring in response to cell injury, indicating the presence of apoptotic tissue. The activation of signaling pathways involved in cell death was confirmed by the immunohistochemical analysis of cleaved caspase-3, suggesting an induction of caspase-3-dependent apoptosis in tumor cells. The induction of cell apoptosis is the primary mechanism of CAP action following the reactive species generated by CAP [19]. However, other cell death pathways have been recently evidenced, such as ferroptosis in tumor cells subjected to CAP treatment [21]. In CCA cell lines, we tested cell media that were first treated by CAP, i.e., PAM. Subsequently, PAM was immediately transferred to the cell culture. Indirect or direct treatment by CAP displays similar efficacy on tumor cell culture, and PAM is also able to reduce tumor burden without inducing side effects when injected intraperitoneally in a murine model of pancreatic cancer [20]. The intraperitoneal injection of PAM lead to reduced metastatic potential of ovarian and gastric cancer cells [22,23]. When we evaluated PAM on CCA cells, although PAM decreased cell survival in both CCA cell lines with similar efficacy, induction of apoptosis was lower in EGI-1 than in the HuCCT1 cells. Doses of CAP used to treat the medium matters and, as suggested in previous studies, low doses of CAP can inhibit cell proliferation without inducing apoptosis, but instead induce senescence [24,25] or autophagy [26,27]. In addition, CAP can affect other cell biology features, for example by inducing endoplasmic reticulum stress, depolarization of mitochondrial membrane potential, DNA damage, or by decreasing migratory and invasive properties [22,28,29], although these aspects deserve further characterization in CCA.

At the molecular level, we detected DNA double strand breaks in both CCA cell lines, along with DNA damage responses with an upregulation of the phosphorylation status of p53 and of CHK1, both regulating cell cycle checkpoints. We previously observed similar DNA damage in CCA cells that were subjected to oxidative stress with hydrogen peroxide [30], suggesting that, upon CAP treatment, CCA cells may undergo oxidative stress. The overload of RONS in CCA cells leads to DNA damage, attested by the phosphorylation of histone $\mathrm{H} 2 \mathrm{AX}$, triggering pathways that will ultimately kill the cancer cells [31]. Altogether, these results fit perfectly with previous finding in other tumors, such as 
oral cancer, were p53 signaling pathway was identified as one of the most deregulated pathways after exposure to PAM by using RNA-sequencing approaches [32].

Specifically targeting tumor cells without damaging healthy cells is a major challenge of anti-cancer treatment. CAP has the advantage to selectively induce cell cycle arrest and death of tumor cells, but not of healthy ones. Whatever the direct/indirect approach, the concept of plasma selectivity is a key issue in treatment. Pioneering studies from Babington et al. have shown that the plasma treatment of mice bearing subcutaneous glioblastoma led to a $56 \%$ decrease of tumor volume while maintaining the viability of healthy cells surrounding the tumor at $85 \%$ [33]. While CAP had a significant effect on CCA cancer cells by decreasing cell viability, it had no deleterious effect on non-malignant liver cells, i.e., primary human hepatocytes, suggesting a selectivity of CAP treatment. By killing primarily cancer cells, plasma treatment preserves healthy tissue and thereby tissue function. Keidar et al. were amongst the first to demonstrate a selectivity of CAP on the lung cancer cell lines vs. normal human bronchial epithelial cells [34]. This selectivity was also emphasized in melanoma cells compared to normal keratinocytes [35], and other cancer types (ovarian, glioblastoma), as a general property of CAP [36]. However, all of these studies deal with cell lines, but none with primary cells. In our studies, hepatocytes were isolated from human liver and cultured according to a well-defined protocol [37]. We found that CAP has no impact on hepatocyte survival or the induction of DNA damage or apoptotic regulatory signaling pathways, in contrast to CCA cell lines. We chose hepatocytes as non-tumor cells, because they are the most abundant cell type of the liver. Although the media composition, an essential parameter [36], was not the same between the two cell types, CAP generated the same profile of RNS in both media and higher ROS in hepatocyte media. Furthermore, hydrogen peroxide increased in CCA cell lines after exposure to PAM, as previously described for atmospheric pressure plasma jets [38], while it remained unchanged in hepatocytes. The cellular mechanisms by which CAP operates this selectivity are still poorly understood and indirect evidence exists to explain this crucial issue. Among the potential mechanisms given so far, aquaporins and anti-oxidant cellular defense systems seem to be the most plausible explanations [4]. Indeed, as happened in our study, elevated expression of ROS-scavenging enzymes, such as superoxide dismutase, catalase, and glutathione reductase, has been observed in healthy cells as compared to tumor cells, which might contribute to cellular defense against CAP-originated reactive species [4].

Finally, one major point that should be considered when CAP treats a tumor is its potential effect on the tumor microenvironment cells. Tumor is a mix of several cell types, including tumor cells, but also CAF, EC, and TAM. According to histological examination of CCA tumors treated with CAP, fibrotic stroma is not affected by CAP treatment, a result that is confirmed by unchanged mRNA expression level of a-SMA, a marker of CAF, between the treated and untreated conditions. As previously shown, fibroblasts are less affected by CAP when compared to cancer cells [20,39]. No obvious change in vascularization is observed, even if plasma has been shown to suppress neovascularization, but not pre-existing vessels, an effect that is partly independent of ROS [40]. Further studies must be conducted in the case of CCA to confirm or not a potential action of CAP on vascular system. Interestingly, one of the most promising views is that CAP treatment is able to activate the immune response in order to attack the tumor [16,41,42]. Indeed, our analysis on tumor xenografts showed changes in the expression of markers related to the TAM phenotype, suggesting a potential shift towards an anti-tumor phenotype of TAM, although this issue deserves further consideration and new research will be undertaken. In vitro studies performed by other groups are in agreement with our findings in vivo, suggesting that increasing the function of pro-inflammatory macrophages might help to control tumorigenesis that is caused by compromised immune response [41]. Taking into account that one of the most therapeutic strategies under study nowadays is the activation of the patient immune system to fight tumors, it is imperative to keep deepening the molecular mechanisms implicated in the effects of CAP on the immune system, especially in immunocompetent murine cancer models, in which not only macrophages, but also lymphocytes, could be potentially involved in this response. 


\section{Materials and Methods}

\subsection{Cell Culture and Treatment}

HuCCT1 cells, which were derived from intrahepatic biliary tract, were kindly provided by Dr. G. Gores (Mayo Clinic, Rochester, MN, USA). EGI-1 cells, derived from extrahepatic biliary tract, were obtained from the German Collection of Microorganisms and Cell Cultures (DSMZ, Braunschweig, Germany). The cells were cultured in DMEM supplemented with $1 \mathrm{~g} / \mathrm{L}$ glucose, $10 \mathrm{mmol} / \mathrm{L} \mathrm{HEPES,}$ $10 \%$ fetal bovine serum (FBS), antibiotics (100 UI/mL penicillin and $100 \mathrm{mg} / \mathrm{mL}$ streptomycin), and antimycotic $(0.25 \mathrm{mg} / \mathrm{mL}$ amphotericin $\mathrm{B})$. Cell lines were routinely screened for the presence of mycoplasma and authenticated for polymorphic markers in order to prevent cross-contamination.

\subsection{Isolation and Culture of Human Hepatocytes}

Normal liver tissue was obtained from adult patients undergoing partial hepatectomy for the treatment of colorectal cancer metastases. Primary human hepatocyte isolation was performed on the ICAN Human HepCell platform, as previously described [43]. Ethical approval for the isolation of human hepatocytes was granted by the Persons Protection Committee (CPP Ile de France III) and by the French Ministry of Health ( $\mathrm{N}^{\circ}$ : COL 2929 and COL 2930). Hepatocytes were isolated while using an established two-step-perfusion protocol with collagenase. First, the tissue was rinsed with pre-warmed $\left(37^{\circ} \mathrm{C}\right)$ calcium-free buffer that was supplemented with $5 \mathrm{mmol} / \mathrm{L}$ ethylene glycol tetraacetic acid (Sigma, Saint-Quentin Fallavier, France). Subsequently, the liver sample was perfused with recirculating perfusion solution containing $5 \mathrm{mg} / \mathrm{mL}$ of collagenase (Sigma) at $37^{\circ} \mathrm{C}$. Afterwards, the tissue was transferred into a petri dish containing a Hepatocyte Wash Medium (Life technologies, Villebon sur Yvette, France). Tissue was mechanically disrupted by shaking and using tweezers to disrupt cells from the remaining scaffold structures. Cellular suspension was filtered through a gauze-lined funnel. The cells were centrifuged at low speed centrifugation (50 g). The supernatant was removed, and pelleted hepatocytes were re-suspended in Hepatocyte Wash Medium. Viability cell was determined by trypan blue exclusion test. Freshly isolated normal hepatocytes were suspended in Williams' medium E (Life Technologies) containing 10\% fetal calf serum (FCS) (Eurobio, Courtaboeuf, France), penicillin-streptomycin (penicillin: $200 \mathrm{U} / \mathrm{mL}$; streptomycin: $200 \mu \mathrm{g} / \mathrm{mL})$, and insulin $(0.1 \mathrm{U} / \mathrm{mL})$. Afterwards, the cells were seeded in 6- and 96-well plates that were pre-coated with type I collagen at a density of $1.8 \times 10^{6}$ and $0.5 \times 10^{5}$ viable cells/well, respectively, and then incubated at $37{ }^{\circ} \mathrm{C}$ in a $5 \% \mathrm{CO}_{2}$ overnight. Then, the medium was replaced with fresh complete hepatocyte medium that was supplemented with $1 \mu \mathrm{mol} / \mathrm{L}$ hydrocortisone hemisuccinate (SERB, Paris, France) and the cells were left in this medium until treatment with plasma activated medium (PAM).

\subsection{Xenograft Tumor Model}

Animal experiments were performed in accordance with the French Animal Research Committee guidelines and a local ethic committee approved all of the procedures (No 10609). $2 \times 10^{6}$ of EGI-1 cells were suspended in $60 \mu \mathrm{L}$ of PBS and $60 \mu \mathrm{L}$ of Matrigel ${ }^{\circledR}$ growth factor reduced (Corning) and implanted subcutaneously into the flank of five-week-old female ATHYM-Foxn1 nu/nu mice (Janvier Labs, Le Genest-Saint-Isle, France). Mice were housed under standard conditions in individually ventilated cages enriched with a nesting material and kept at $22{ }^{\circ} \mathrm{C}$ on a $12 \mathrm{~h}$ light/12 h dark cycle with ad libitum access to food and tap water. Tumor growth was monitored by measuring every 2-3 days the tumor volume (V xenograft) with a caliper, as follows: $\mathrm{V}$ xenograft $=x \times y^{2} / 2$ where $x$ and $y$ are the longest and shortest lateral diameters, respectively. Once the tumor volume reached approximately $200 \mathrm{~mm}^{3}$, CAP and gemcitabine treatments were initiated. Gemcitabine was administered every Monday and Thursday during three weeks by intraperitoneal injection at a concentration of $120 \mathrm{mg} / \mathrm{kg}$ dissolved in saline solution (vehicle). Cold atmospheric plasma was administered, as explained in Section 4.4, the same days as gemcitabine. 


\subsection{Cold Atmospheric Plasma Treatment}

The in vivo and the in vitro experiments were conducted while using the same atmospheric pressure plasma jet device, called PTJ, as sketched in Figure 1a. It is composed of a $10 \mathrm{~cm}$ long dielectric quartz tube presenting a $4 \mathrm{~mm}$ inner diameter and a $2 \mathrm{~mm}$ wall thickness. Its electrode configuration is made of two outer ring electrodes with inner and outer diameters of $8 \mathrm{~mm}$ and $12.8 \mathrm{~mm}$, respectively, while the inter-ring distance is $50 \mathrm{~mm}$. For all experiments, the lower ring electrode was connected to the ground, while the upper ring electrode was biased to the high voltage. The PTJ was supplied with helium gas (flow rate of $1 \mathrm{slm}$ ) and powered with a nanopulse high voltage generator device (model Nanogen 1) from RLC Electronic Company. For both in vivo and in vitro experiments, electrical parameters were fixed, as follows: $9 \mathrm{kV}$ of amplitude, $14 \%$ of duty cycle, and $30 \mathrm{kHz}$ of repetition frequency. The reasons explaining how these values were chosen as well as the physico-chemical characterizations of the PTJ device have already been published in [9]. For the in vivo studies, the cold atmospheric plasma was applied to the animals, as previously described [9], $9 \mathrm{kV}, 30 \mathrm{kHz}, 14 \%$, maintaining a gap of $10 \mathrm{~mm}$ between the tube and the skin. For the in vitro studies, the cells were treated with PAM. In order to maintain reproducibility among different plastic supports, $3 \mathrm{~mL}$ of the corresponding culture media in a 6-well plate were treated with the same conditions $(9 \mathrm{kV}, 30 \mathrm{kHz}$, $14 \%$ ) during 1, 3, 5, or $10 \mathrm{~min}$. A gap of $7 \mathrm{~mm}$ between the tube and the surface of medium was constantly maintained. After treatments, PAM was transferred to 96-, 24-, or 6-well plates, according to the different analysis performed (Figure S1).

\subsection{Biochemistry}

The concentrations of alanine aminotransferase (ALAT), aspartate aminotransferase (ASAT), and lactate dehydrogenase (LDH) in the plasma of mice were measured on an Olympus AU400 Analyzer.

\subsection{Histology and (Immuno)Histochemistry}

Formalin-fixed paraffin-embedded tissue samples from mice xenografts were cut in $4 \mu \mathrm{m}$ sections, deparaffined, and stained with hematoxylin and eosin to observe tissue histology.

For immunohistochemistry, the antigens were unmasked, as indicated in Table 1. For cleaved -caspase-3 and 8-oxoguanine, the sections were sequentially incubated with $\mathrm{H}_{2} \mathrm{O}_{2}$ for 5 min. (only for caspase3), with Protein Block (Novolink Polymer Detection System; Novocastra Laboratories Ltd., Nanterre, France) for $5 \mathrm{~min}$., and with primary antibodies for $30 \mathrm{~min}$. (overnight for 8-oxoguanine). Novolink Post Primary was applied for $15 \mathrm{~min}$. The sections were finally washed and incubated with Novolink Polymer for $15 \mathrm{~min}$. An automated staining system (Autostainer Plus, Dakocytomation, Les Ulis, France) was used to perform immunostaining. The color was developed while using amino-ethyl-carbazole (AEC peroxidase substrate kit; Vector Laboratories, Le Perray-en-Yvelines, France). The sections were counterstained with hematoxylin and then mounted with glycergel (Dako). For F4/80 immunostaining, sections were incubated with PBS 0.5\% triton X-100 30 min. to increase the permeabilization of the tissue. Subsequently, they were blocked with horse serum $2.5 \%$ (Vector) during $1 \mathrm{~h}$. After tissue blocking, the samples were immunostained with primary antibody overnight at $4{ }^{\circ} \mathrm{C}$. Afterwards, endogenous peroxidase blocking was performed with hydrogen peroxide solution (Leica) during $1 \mathrm{~h}$. The samples were developed with the ImPRESS Excel staining kit (Vector) following manufacturer instruction. Briefly, the tissue samples were incubated with anti-rabbit Ig secondary antibody for 90 min washed with PBS, and then incubated with an anti-goat amplifier antibody for $1 \mathrm{~h}$. Finally, the samples were developed with peroxidase substrate for $3 \mathrm{~min}$. and counterstained with Mayer's hematoxylin (Dako) for $5 \mathrm{~min}$. 
Table 1. Primary antibodies used for immunodetection.

\begin{tabular}{cccccc}
\hline Name & Species & Manufacturer & Reference & Dilution & Antigen Unmasking \\
\hline 8-oxoguanine & $\mathrm{M}$ & Abcam & ab206461 & $1 / 100(\mathrm{IHC})$ & EDTA pH8 \\
cCaspase3 & $\mathrm{R}$ & CST & CST9664 & $1 / 100(\mathrm{IHC})$ & Citrate pH6 \\
CPARP & $\mathrm{R}$ & CST & CST5625 & $1 / 1000(\mathrm{WB})$ & \\
CHK1 & $\mathrm{M}$ & CST & CST2360 & $1 / 1000(\mathrm{WB})$ & \\
pCHK1 & $\mathrm{R}$ & CST & CST2348 & $1 / 1000(\mathrm{WB})$ & \\
F4/80 & $\mathrm{R}$ & Spring Bioscience & M4154 & $1 / 100(\mathrm{IHC})$ & Citrate pH6 \\
GAPDH & $\mathrm{M}$ & Santa Cruz & sc-32233 & $1 / 5000(\mathrm{WB})$ & \\
p53 & $\mathrm{M}$ & Santa Cruz & sc-126 & $1 / 500(\mathrm{WB})$ & \\
pp53 & $\mathrm{R}$ & CST & CST9284 & $1 / 1000(\mathrm{WB})$ & \\
$\gamma$ H2A.X & $\mathrm{R}$ & CST & CST9718 & $1 / 1000(\mathrm{WB}), 1 / 200(\mathrm{IF})$ & \\
\hline
\end{tabular}

$\mathrm{M}$, mouse; R, rabbit; WB, western blot; IF, immunofluorescence; IHC, immunohistochemistry.

\subsection{Cell Viability}

5000 EGI-1 cells/well, 4000 HuCCT1 cells/well, and 50,000 hepatocytes/well were plated in 96-well plates. $24 \mathrm{~h}$ later, fresh culture medium, PAM, or gemcitabine replaced the medium. The cells were then incubated for $72 \mathrm{~h}$ before determining the viability by the crystal violet method. Absorbance was quantified with a spectrophotometer (Tecan) at $595 \mathrm{~nm}$.

\subsection{RONS Determination in Culture Media}

Nitrites and $\mathrm{H}_{2} \mathrm{O}_{2}$ concentrations were measured using Griess reagent (Sigma Aldrich, Saint-Quentin Fallavier, France) and Titanium Sulfate $\mathrm{TiSO}_{4}$ (Sigma-Aldrich, Saint-Quentin Fallavier, France), respectively, to verify whether reactive species are produced in PAM. In the presence of nitrite species, the Griess reagent shows an absorption peak at $518 \mathrm{~nm}$ (pink coloration), while, in the presence of peroxide, the $\mathrm{TiSO}_{4}$ shows an absorption peak at $405 \mathrm{~nm}$ (yellow coloration) both measured with the Biotek Cytation 3 device. A two-steps protocol was followed: first, the media were placed in 6-well plates and exposed to plasma, as previously explained in Section 4.4. Second, plasma was switched off. For the nitrite determination, $25 \mathrm{~mL}$ of each culture media sample was mixed with $175 \mathrm{~mL}$ of distilled water and $50 \mathrm{~mL}$ of Griess reagent. For the peroxide determination, $250 \mathrm{~mL}$ of each culture media sample was mixed with $100 \mathrm{~mL}$ of $\mathrm{TiSO}_{4}$.

\subsection{ROS Determination in Cell Lysates}

ROS production was assessed using the 2', $7^{\prime}$-dichlorofluorescein diacetate (H2DCFDA; Abcam cat number ab113851) according to the instructions. Briefly, the CCA cells and hepatocytes were plated at $2.5 \times 10^{5}$ cells/well and $0.5 \times 10^{5}$ cells/well, respectively, in black-walled, clear-bottom 96-well microplates, and then incubated for $24 \mathrm{~h}$ at $37^{\circ} \mathrm{C}$. The cells were incubated with CM-H2DCFDA $(25 \mu \mathrm{M})$ in PBS for $30 \mathrm{~min}$. and then with PAM for $30 \mathrm{~min}$. The cells were washed with PBS, and fluorescence was measured at 485/535 nm (Tecan, Lyon, France). Normalization was done by the crystal violet method.

\subsection{Apoptosis Assay}

$2 \times 10^{5}$ EGI-1 cells/well and $1.5 \times 10^{5} \mathrm{HuCCT1}$ cells/well were plated in 6-well plates. $24 \mathrm{~h}$ later, the medium was replaced by fresh culture medium or PAM. $48 \mathrm{~h}$ or $72 \mathrm{~h}$ later both cells from the supernatant and the plates were collected and stained while using the PE Annexin V Apoptosis Detection Kit with 7-AAD (BioLegend, London, UK), according to the manufacturer's instructions. Flow-cytometric analysis was performed using a Gallios flow cytometer (Beckman-Coulter, Villepinte, France) to calculate the apoptosis rate. The results were analyzed using Kaluza analysis software (Beckman-Coulter). 


\subsection{Immunofluorescence}

Immunofluorescence assays were performed, as previously described [44]. Table 1 provides the primary antibodies. The cells were observed with an Olympus Bx 61 microscope (Olympus, Rungis, France).

\subsection{Western Blot Analysis}

For obtaining whole-cell lysates for WB, the cell cultures were lysed in RIPA buffer supplemented with $1 \mathrm{mmol} / \mathrm{L}$ orthovanadate and a cocktail of protease inhibitors. Proteins were quantified using a BCA kit (Pierce, Lllkirch, France). WB analyses were performed, as previously described [44]. Table 1 provides the primary antibodies.

\subsection{Cell Cycle Analysis}

$0.6 \times 10^{5}$ EGI-1 cells/well and $0.5 \times 10^{5} \mathrm{HuCCT1}$ cells/well were seeded in 6-well plates and incubated for $24 \mathrm{~h}$. The cells were then treated with PAM for $24 \mathrm{~h}$. The cells are detached with trypsin, washed with cold PBS, pooled, and centrifuged before being fixed in $70 \%$ ice-cold ethanol during $30 \mathrm{~min}$. at $-20^{\circ} \mathrm{C}$, and stored at $-20{ }^{\circ} \mathrm{C}$ if required. The cells are incubated with $100 \mu \mathrm{g} / \mathrm{mL}$ of RNase A and $40 \mu \mathrm{g} / \mathrm{mL}$ of propidium iodide in PBS buffer. The stained cells were analyzed with a CytoFLEX (Beckman-Coulter), and their distribution in different phases of the cell cycle was calculated using Kaluza analysis software 2.0 (Beckman Coulter, Brea, CA, USA).

\subsection{RNA and Reverse Transcription-PCR}

Total RNA extraction and RT-qPCR was performed as previously described [44]. Table 2 provides the primer sequences. Gene expression was normalized to Hprt1 mRNA content for mouse genes and was expressed relatively to the control condition of each experiment. The relative expression of each target gene was determined from replicate samples using the formula $2^{-\Delta \Delta C t}$.

Table 2. Mouse primer used for quantitative real-time PCR.

\begin{tabular}{cccc}
\hline Gene & Protein & Forward $\left(\mathbf{5}^{\prime} \rightarrow \mathbf{3}^{\prime} \mathbf{)}\right.$ & Reverse $\mathbf{( 5}^{\prime} \rightarrow \mathbf{3}^{\prime} \mathbf{)}$ \\
\hline Acta2 & $\alpha$-Sma & CTGTCAGGAACCCTGAGACGCT & TACTCCCTGATGTCTGGGAC \\
Pecam 1 & CD31 & AGCCTCCAGGCTGAGGAAAA & GATGTCCACAAGGCACTCCA \\
Ccr 2 & Ccr2 & GGCCACCACACCGTATGACTA & AGAGATGGCCAAGTTGAGCAGATAG \\
Adgre 1 & F4-80 & CTTTGGCTATGGGCTTCCAGTC & GCAAGGAGGACAGAGTTTATCGTG \\
Il $1 b$ & Il1 $\beta$ & GCAACTGTTCCTGAACTCAACT & ATCTTTTGGGGTCCGTCAACT \\
Ccl 2 & Mcp1 & GCCTGCTGTTCACAGTTGC & CAGGTGAGTGGGGCGTTA \\
Tnfa & Tnfa & CCCTCACACTCAGATCATCTTCT & GCTACGACGTGGGCTACAG \\
Tnfsf 10 & Trail & GCTCCTGCAGGCTGTGTC & CCAATTTTGGAGTAATTGTCCTG \\
Hprt1 & Hprt & TCAGTCAACGGGGGACATAA & TGCTTAACCAGGGAAAGCAAA \\
\hline
\end{tabular}

\subsection{Statistics}

The results were analyzed using the GraphPad Prism 5.0 statistical software (GraphPad Software, San Diego, CA, USA). Data are shown as means \pm standard error of the mean (SEM). For comparisons between two groups, parametric Student $t$ test or nonparametric Mann-Whitney test were used. For comparisons between more than two groups, parametric one-way ANOVA test followed by a posteriori Bonferroni test was used.

\section{Conclusions}

Our results indicate that CAP is able to reduce CCA progression through the induction of DNA damage, which leads to cell cycle arrest and apoptosis of tumor cells, together with potential effects in the immune microenvironment in terms of the phenotypic change of TAM. These evidences support the potential usefulness of CAP as a future tool to treat CCA. However, several questions remain to 
be solved before reaching application in CCA patients. First, the effect of CAP on healthy liver cells must be evaluated in preclinical orthotopic models of CCA to assess the level of side damaging effects after a direct CAP treatment to the liver. Moreover, to reach human applicability, the size of the CAP applicating device must be reduced and adapted to the human anatomy and localization of biliary tumors. Therefore, although CAP is a novel promising anticancer "agent", further investigation is needed to include it in the therapeutic arsenal of CCA in the future.

Supplementary Materials: The following are available online at http://www.mdpi.com/2072-6694/12/5/1280/s1, Figure S1: Schematic representation of in vitro treatment of CCA cell lines and hepatocytes with PAM, Figure S2: (a) Representative images of western blot analysis of cleaved PARP, phosphorylated and total p53, phosphorylated and total CHK1 and phosphorylated H2AX in hepatocytes after $24 \mathrm{~h}, 48 \mathrm{~h}$ and $72 \mathrm{~h}$ of exposure to culture medium pretreated with CAP for $3 \mathrm{~min}$. ( $9 \mathrm{kV}, 30 \mathrm{kHz}, 14 \%$, gap of $7 \mathrm{~mm})$. (b) Representative images of western blot analysis of cleaved PARP, phosphorylated and total p53, phosphorylated and total CHK1 and phosphorylated $\mathrm{H} 2 \mathrm{AX}$ in EGI-1 and HuCCT1 after $24 \mathrm{~h}, 48 \mathrm{~h}$ and $72 \mathrm{~h}$ of exposure to 0.1 and $0.01 \mu \mathrm{M}$ of gemcitabine, respectively. (c) Representative images of western blot analysis of cleaved PARP, phosphorylated and total p53, phosphorylated and total CHK1 and phosphorylated $\mathrm{H} 2 \mathrm{AX}$ in hepatocytes after $72 \mathrm{~h}$ of exposure to increasing doses of gemcitabine. (d) Representative images of western blot analysis of cleaved PARP, phosphorylated and total p53, phosphorylated and total CHK1 and phosphorylated H2AX in hepatocytes after $24 \mathrm{~h}, 48 \mathrm{~h}$ and $72 \mathrm{~h}$ of exposure to $10 \mu \mathrm{M}$ of gemcitabine, Figures S3-S15: Detailed information of western blot.

Author Contributions: Conceptualization, J.V., F.J., T.D., and L.F.; methodology, J.V., F.J., M.V., H.D., A.A., L.A., E.G.-S., and F.M.; validation, J.V., F.J., H.D.; formal analysis, J.V., F.J., H.D., J.A., and T.D.; investigation, J.V., F.J., M.V., H.D., A.A., L.A., and F.M.; resources, J.V., F.J., M.V., H.D., L.A., O.S., T.D., and L.F.; data curation, J.V., M.V., H.D., A.A., L.A., T.D., and L.F.; writing-original draft preparation, J.V., T.D., and L.F; writing-review and editing, J.V., H.D., A.A., L.A., E.G.-S., C.H., T.D., and L.F.; visualization, J.V., T.D., and L.F.; supervision, J.V., T.D., and L.F.; project administration, J.V., T.D., and L.F.; funding acquisition, L.A., T.D., and L.F. All authors have read and agreed to the published version of the manuscript.

Funding: J.V. and F.J. are recipient of the LABEX PLAS@PAR (ANR-11-IDEX-0004-02). This work was funded by the LABEX Plas@par project, and received financial state aid managed by the Agence Nationale de la Recherche, as part of the programme "Investissements d'avenir" (ANR-11-IDEX-0004-02), the program Emergence @ Sorbonne Université 2016, the French Ministry of Solidarity and Health and Inserm, INCA-DGOS-Inserm_12560), the « Région Ile-de-France » (Sesame, Ref. 16016309) and the Platform program of Sorbonne Université. T.D. and L.F. are supported by "le programme Emergence 2019 Cancéropôle Ile de France" (Projet ASCLEPIOS 193602) et "le programme Amorçage 2019 SiRIC Curamus" (Projet PROMISE 195741). L.F. is supported by Agence Nationale de la Recherche (ANR-17-CE14-0013-01) and A.A. by Fondation pour la Recherche Médicale (FRM SPF201809007054).

Acknowledgments: The authors acknowledge Tatiana Ledent and her team from Housing and experimental animal facility (HEAF), Centre de recherche Saint-Antoine (CRSA), Brigitte Solhonne from the histomorphology Platform, UMS 30 Lumic, Centre de recherche Saint-Antoine (CRSA). Annie Munier and Romain Morichon from the Flow cytometry-imaging platform UMS_30 LUMIC, CRSA, Haquima El-Mourabit, Nathalie Ferrand, Jean-Alain Martignoles and Maxime Tenon from CRSA for their help in flow cytometry, and Elisabeth Lasnier for plasma biochemistry dosages (Biochemistry Department Saint-Antoine Hospital).

Conflicts of Interest: The authors declare no conflict of interest.

\section{References}

1. Banales, J.M.; Cardinale, V.; Carpino, G.; Marzioni, M.; Andersen, J.B.; Invernizzi, P.; Lind, G.E.; Folseraas, T.; Forbes, S.J.; Fouassier, L.; et al. Expert consensus document: Cholangiocarcinoma: Current knowledge and future perspectives consensus statement from the European Network for the Study of Cholangiocarcinoma (ENS-CCA). Nat. Rev. Gastroenterol. Hepatol. 2016, 13, 261-280. [CrossRef] [PubMed]

2. Valle, J.; Wasan, H.; Palmer, D.H.; Cunningham, D.; Anthoney, A.; Maraveyas, A.; Madhusudan, S.; Iveson, T.; Hughes, S.; Pereira, S.P.; et al. Cisplatin plus gemcitabine versus gemcitabine for biliary tract cancer. N. Engl. J. Med. 2010, 362, 1273-1281. [CrossRef]

3. Dai, X.; Bazaka, K.; Richard, D.J.; Thompson, E.R.W.; Ostrikov, K.K. The Emerging Role of Gas Plasma in Oncotherapy. Trends Biotechnol. 2018, 36, 1183-1198. [CrossRef] [PubMed]

4. Yan, D.; Sherman, J.H.; Keidar, M. Cold atmospheric plasma, a novel promising anti-cancer treatment modality. Oncotarget 2017, 8, 15977-15995. [CrossRef] [PubMed]

5. Smolkova, B.; Lunova, M.; Lynnyk, A.; Uzhytchak, M.; Churpita, O.; Jirsa, M.; Kubinova, S.; Lunov, O.; Dejneka, A. Non-Thermal Plasma, as a New Physicochemical Source, to Induce Redox Imbalance and Subsequent Cell Death in Liver Cancer Cell Lines. Cell. Physiol. Biochem. 2019, 52, 119-140. 
6. Vandamme, M.; Robert, E.; Lerondel, S.; Sarron, V.; Ries, D.; Dozias, S.; Sobilo, J.; Gosset, D.; Kieda, C.; Legrain, B.; et al. ROS implication in a new antitumor strategy based on non-thermal plasma. Int. J. Cancer 2012, 130, 2185-2194. [CrossRef]

7. Ahn, H.J.; Kim, K.I.; Hoan, N.N.; Kim, C.H.; Moon, E.; Choi, K.S.; Yang, S.S.; Lee, J.S. Targeting cancer cells with reactive oxygen and nitrogen species generated by atmospheric-pressure air plasma. PLoS ONE 2014, 9, e86173. [CrossRef]

8. Adachi, T.; Tanaka, H.; Nonomura, S.; Hara, H.; Kondo, S.; Hori, M. Plasma-activated medium induces A549 cell injury via a spiral apoptotic cascade involving the mitochondrial-nuclear network. Free Radic. Biol. Med. 2015, 79, 28-44. [CrossRef]

9. Judée, F.; Vaquero, J.; Guégan, S.; Fouassier, L.; Dufour, T. Atmospheric pressure plasma jets applied to cancerology: Correlating electrical configuration with in vivo toxicity and therapeutic efficiency. J. Phys. D Appl. Phys. 2019, 52, 245201. [CrossRef]

10. Lin, G.; Lin, K.J.; Wang, F.; Chen, T.C.; Yen, T.C.; Yeh, T.S. Synergistic antiproliferative effects of an mTOR inhibitor (rad001) plus gemcitabine on cholangiocarcinoma by decreasing choline kinase activity. Dis. Model. Mech. 2018, 11. [CrossRef]

11. Luo, X.Y.; Meng, X.J.; Cao, D.C.; Wang, W.; Zhou, K.; Li, L.; Guo, M.; Wang, P. Transplantation of bone marrow mesenchymal stromal cells attenuates liver fibrosis in mice by regulating macrophage subtypes. Stem Cell Res. Ther. 2019, 10, 16. [CrossRef] [PubMed]

12. Brulle, L.; Vandamme, M.; Ries, D.; Martel, E.; Robert, E.; Lerondel, S.; Trichet, V.; Richard, S.; Pouvesle, J.M.; Le Pape, A. Effects of a non thermal plasma treatment alone or in combination with gemcitabine in a MIA PaCa2-luc orthotopic pancreatic carcinoma model. PLoS ONE 2012, 7, e52653. [CrossRef] [PubMed]

13. Hattori, N.; Yamada, S.; Torii, K.; Takeda, S.; Nakamura, K.; Tanaka, H.; Kajiyama, H.; Kanda, M.; Fujii, T.; Nakayama, G.; et al. Effectiveness of plasma treatment on pancreatic cancer cells. Int. J. Oncol. 2015, 47, 1655-1662. [CrossRef] [PubMed]

14. Utsumi, F.; Kajiyama, H.; Nakamura, K.; Tanaka, H.; Mizuno, M.; Ishikawa, K.; Kondo, H.; Kano, H.; Hori, M.; Kikkawa, F. Effect of indirect nonequilibrium atmospheric pressure plasma on anti-proliferative activity against chronic chemo-resistant ovarian cancer cells in vitro and in vivo. PLoS ONE 2013, 8, e81576. [CrossRef] [PubMed]

15. Xiang, L.; Xu, X.; Zhang, S.; Cai, D.; Dai, X. Cold atmospheric plasma conveys selectivity on triple negative breast cancer cells both in vitro and in vivo. Free Radic. Biol. Med. 2018, 124, 205-213. [CrossRef] [PubMed]

16. Freund, E.; Liedtke, K.R.; van der Linde, J.; Metelmann, H.R.; Heidecke, C.D.; Partecke, L.I.; Bekeschus, S. Physical plasma-treated saline promotes an immunogenic phenotype in CT26 colon cancer cells in vitro and in vivo. Sci. Rep. 2019, 9, 634. [CrossRef]

17. Binenbaum, Y.; Ben-David, G.; Gil, Z.; Slutsker, Y.Z.; Ryzhkov, M.A.; Felsteiner, J.; Krasik, Y.E.; Cohen, J.T. Cold Atmospheric Plasma, Created at the Tip of an Elongated Flexible Capillary Using Low Electric Current, Can Slow the Progression of Melanoma. PLoS ONE 2017, 12, e0169457. [CrossRef]

18. Chen, Z.; Simonyan, H.; Cheng, X.; Gjika, E.; Lin, L.; Canady, J.; Sherman, J.H.; Young, C.; Keidar, M. A Novel Micro Cold Atmospheric Plasma Device for Glioblastoma Both In Vitro and In Vivo. Cancers 2017, 9, 61. [CrossRef]

19. Dubuc, A.; Monsarrat, P.; Virard, F.; Merbahi, N.; Sarrette, J.P.; Laurencin-Dalicieux, S.; Cousty, S. Use of cold-atmospheric plasma in oncology: A concise systematic review. Ther. Adv. Med. Oncol. 2018, 10. [CrossRef]

20. Liedtke, K.R.; Bekeschus, S.; Kaeding, A.; Hackbarth, C.; Kuehn, J.P.; Heidecke, C.D.; von Bernstorff, W.; von Woedtke, T.; Partecke, L.I. Non-thermal plasma-treated solution demonstrates antitumor activity against pancreatic cancer cells in vitro and in vivo. Sci. Rep. 2017, 7, 8319. [CrossRef]

21. Furuta, T.; Shi, L.; Toyokuni, S. Non-thermal plasma as a simple ferroptosis inducer in cancer cells: A possible role of ferritin. Pathol. Int. 2018, 68, 442-443. [CrossRef] [PubMed]

22. Nakamura, K.; Peng, Y.; Utsumi, F.; Tanaka, H.; Mizuno, M.; Toyokuni, S.; Hori, M.; Kikkawa, F.; Kajiyama, H. Novel Intraperitoneal Treatment With Non-Thermal Plasma-Activated Medium Inhibits Metastatic Potential of Ovarian Cancer Cells. Sci. Rep. 2017, 7, 6085. [CrossRef] [PubMed] 
23. Takeda, S.; Yamada, S.; Hattori, N.; Nakamura, K.; Tanaka, H.; Kajiyama, H.; Kanda, M.; Kobayashi, D.; Tanaka, C.; Fujii, T.; et al. Intraperitoneal Administration of Plasma-Activated Medium: Proposal of a Novel Treatment Option for Peritoneal Metastasis From Gastric Cancer. Ann. Surg. Oncol. 2017, 24, 1188-1194. [CrossRef] [PubMed]

24. Arndt, S.; Wacker, E.; Li, Y.F.; Shimizu, T.; Thomas, H.M.; Morfill, G.E.; Karrer, S.; Zimmermann, J.L.; Bosserhoff, A.K. Cold atmospheric plasma, a new strategy to induce senescence in melanoma cells. Exp. Dermatol. 2013, 22, 284-289. [CrossRef]

25. Schneider, C.; Gebhardt, L.; Arndt, S.; Karrer, S.; Zimmermann, J.L.; Fischer, M.J.M.; Bosserhoff, A.K. Cold atmospheric plasma causes a calcium influx in melanoma cells triggering CAP-induced senescence. Sci. Rep. 2018, 8, 10048. [CrossRef]

26. Shi, L.; Ito, F.; Wang, Y.; Okazaki, Y.; Tanaka, H.; Mizuno, M.; Hori, M.; Hirayama, T.; Nagasawa, H.; Richardson, D.R.; et al. Non-thermal plasma induces a stress response in mesothelioma cells resulting in increased endocytosis, lysosome biogenesis and autophagy. Free Radic. Biol. Med. 2017, 108, 904-917. [CrossRef]

27. Ito, T.; Ando, T.; Suzuki-Karasaki, M.; Tokunaga, T.; Yoshida, Y.; Ochiai, T.; Tokuhashi, Y.; Suzuki-Karasaki, Y. Cold PSM, but not TRAIL, triggers autophagic cell death: A therapeutic advantage of PSM over TRAIL. Int. J. Oncol. 2018, 53, 503-514. [CrossRef]

28. Ruwan Kumara, M.H.; Piao, M.J.; Kang, K.A.; Ryu, Y.S.; Park, J.E.; Shilnikova, K.; Jo, J.O.; Mok, Y.S.; Shin, J.H.; Park, Y.; et al. Non-thermal gas plasma-induced endoplasmic reticulum stress mediates apoptosis in human colon cancer cells. Oncol. Rep. 2016, 36, 2268-2274. [CrossRef]

29. Chang, J.W.; Kang, S.U.; Shin, Y.S.; Kim, K.I.; Seo, S.J.; Yang, S.S.; Lee, J.S.; Moon, E.; Lee, K.; Kim, C.H. Non-thermal atmospheric pressure plasma inhibits thyroid papillary cancer cell invasion via cytoskeletal modulation, altered MMP-2/-9/uPA activity. PLoS ONE 2014, 9, e92198. [CrossRef]

30. Nguyen Ho-Bouldoires, T.H.; Claperon, A.; Mergey, M.; Wendum, D.; Desbois-Mouthon, C.; Tahraoui, S.; Fartoux, L.; Chettouh, H.; Merabtene, F.; Scatton, O.; et al. Mitogen-activated protein kinase-activated protein kinase 2 mediates resistance to hydrogen peroxide-induced oxidative stress in human hepatobiliary cancer cells. Free Radic. Biol. Med. 2015, 89, 34-46. [CrossRef]

31. Matt, S.; Hofmann, T.G. The DNA damage-induced cell death response: A roadmap to kill cancer cells. Cell Mol. Life Sci. 2016, 73, 2829-2850. [CrossRef] [PubMed]

32. Shi, L.; Yu, L.; Zou, F.; Hu, H.; Liu, K.; Lin, Z. Gene expression profiling and functional analysis reveals that p53 pathway-related gene expression is highly activated in cancer cells treated by cold atmospheric plasma-activated medium. PeerJ 2017, 5, e3751. [CrossRef] [PubMed]

33. Babington, P.; Rajjoub, K.; Canady, J.; Siu, A.; Keidar, M.; Sherman, J.H. Use of cold atmospheric plasma in the treatment of cancer. Biointerphases 2015, 10, 029403. [CrossRef] [PubMed]

34. Keidar, M.; Walk, R.; Shashurin, A.; Srinivasan, P.; Sandler, A.; Dasgupta, S.; Ravi, R.; Guerrero-Preston, R.; Trink, B. Cold plasma selectivity and the possibility of a paradigm shift in cancer therapy. Br. J. Cancer 2011, 105, 1295-1301. [CrossRef]

35. Zucker, S.N.; Zirnheld, J.; Bagati, A.; DiSanto, T.M.; Des Soye, B.; Wawrzyniak, J.A.; Etemadi, K.; Nikiforov, M.; Berezney, R. Preferential induction of apoptotic cell death in melanoma cells as compared with normal keratinocytes using a non-thermal plasma torch. Cancer Biol. Ther. 2012, 13, 1299-1306. [CrossRef]

36. Biscop, E.; Lin, A.; Boxem, W.V.; Loenhout, J.V.; Backer, J.; Deben, C.; Dewilde, S.; Smits, E.; Bogaerts, A.A. Influence of Cell Type and Culture Medium on Determining Cancer Selectivity of Cold Atmospheric Plasma Treatment. Cancers (Basel) 2019, 11, 1287. [CrossRef]

37. Aoudjehane, L.; Podevin, P.; Scatton, O.; Jaffray, P.; Dusanter-Fourt, I.; Feldmann, G.; Massault, P.P.; Grira, L.; Bringuier, A.; Dousset, B.; et al. Interleukin-4 induces human hepatocyte apoptosis through a Fas-independent pathway. FASEB J. 2007, 21, 1433-1444. [CrossRef]

38. Kurake, N.; Tanaka, H.; Ishikawa, K.; Kondo, T.; Sekine, M.; Nakamura, K.; Kajiyama, H.; Kikkawa, F.; Mizuno, M.; Hori, M. Cell survival of glioblastoma grown in medium containing hydrogen peroxide and/or nitrite, or in plasma-activated medium. Arch. Biochem. Biophys. 2016, 605, 102-108. [CrossRef]

39. Liedtke, K.R.; Diedrich, S.; Pati, O.; Freund, E.; Flieger, R.; Heidecke, C.D.; Partecke, L.I.; Bekeschus, S. Cold Physical Plasma Selectively Elicits Apoptosis in Murine Pancreatic Cancer Cells In Vitro and In Ovo. Anticancer Res. 2018, 38, 5655-5663. [CrossRef] 
40. Ye, F.; Kaneko, H.; Nagasaka, Y.; Ijima, R.; Nakamura, K.; Nagaya, M.; Takayama, K.; Kajiyama, H.; Senga, T.; Tanaka, H.; et al. Plasma-activated medium suppresses choroidal neovascularization in mice: A new therapeutic concept for age-related macular degeneration. Sci. Rep. 2015, 5, 7705. [CrossRef]

41. Kaushik, N.K.; Kaushik, N.; Adhikari, M.; Ghimire, B.; Linh, N.N.; Mishra, Y.K.; Lee, S.J.; Choi, E.H. Preventing the Solid Cancer Progression via Release of Anticancer-Cytokines in Co-Culture with Cold Plasma-Stimulated Macrophages. Cancers (Basel) 2019, 11, 842. [CrossRef] [PubMed]

42. Azzariti, A.; Iacobazzi, R.M.; Di Fonte, R.; Porcelli, L.; Gristina, R.; Favia, P.; Fracassi, F.; Trizio, I.; Silvestris, N.; Guida, G.; et al. Plasma-activated medium triggers cell death and the presentation of immune activating danger signals in melanoma and pancreatic cancer cells. Sci. Rep. 2019, 9, 4099. [CrossRef] [PubMed]

43. Aoudjehane, L.; Gautheron, J.; Le Goff, W.; Goumard, C.; Gilaizeau, J.; Nget, C.S.; Savier, E.; Atif, M.; Lesnik, P.; Morichon, R.; et al. Novel defatting strategies reduce lipid accumulation in primary human culture models of liver steatosis. Dis. Model. Mech. 2020. [CrossRef] [PubMed]

44. Vaquero, J.; Lobe, C.; Tahraoui, S.; Claperon, A.; Mergey, M.; Merabtene, F.; Wendum, D.; Coulouarn, C.; Housset, C.; Desbois-Mouthon, C.; et al. The IGF2/IR/IGF1R Pathway in Tumor Cells and Myofibroblasts Mediates Resistance to EGFR Inhibition in Cholangiocarcinoma. Clin. Cancer Res. 2018, 24, 4282-4296. [CrossRef] [PubMed]

(C) 2020 by the authors. Licensee MDPI, Basel, Switzerland. This article is an open access article distributed under the terms and conditions of the Creative Commons Attribution (CC BY) license (http://creativecommons.org/licenses/by/4.0/). 